\title{
Intervenciones en los Dólmenes de Antequera (1840-2020). Una revisión crítica*
}

\author{
Interventions in the Antequera Dolmens (1840-2020). A critical review
}

\author{
Coronada Mora Molinaa y Leonardo García Sanjuána
}

\begin{abstract}
RESUMEN
Los monumentos megalíticos de Antequera (Málaga) han sido objeto de numerosas excavaciones arqueológicas, trabajos de restauración y proyectos de "urbanización" desde que entre 1842 y 1847 se iniciara la excavación de Menga y en 1903 y 1904 la exploración de Viera y El Romeral. El objetivo principal de estas intervenciones ha sido ampliar el conocimiento sobre las construcciones prehistóricas, mejorar su estado de conservación y facilitar su acceso al público. Sin embargo, muchas de ellas han tenido consecuencias negativas para la conservación y el conocimiento científico de los monumentos. Este artículo valora críticamente estas intervenciones a partir del análisis de la documentación disponible, consistente en proyectos previos, informes y memorias, planimetría, fotografías y publicaciones. Además, planteamos un conjunto de criterios que todas las actividades futuras realizadas en los megalitos antequeranos y sus alrededores deberían cumplir para evitar el deterioro y la pérdida de registro arqueológico.
\end{abstract}

\begin{abstract}
The Antequera dolmens have been the object of numerous archaeological excavations, restoration work and "urbanisation" projects since the first explorations were carried out at Menga between 1842 and 1847, and at Viera and El Romeral in 1903 and 1904 respectively. Although the main aim of these interventions was to increase the existing knowledge on these prehistoric constructions, improve their state of preservation and make them accessible to the wider public, the truth is that many of them had negative consequences for their conservation and scientific knowledge. In this paper, we attempt a critical valuation of the long history of interventions at the site, based on the analysis of the available documentation, including 'grey literature' (planning documents, projects, re-
\end{abstract}

ports, planimetry and photographs) as well as published material. As a result, we propose a set of criteria that all future activities carried out at the site and its surroundings should meet in order to avoid previous problems, including the deterioration of the monuments themselves and losses to the archaeological record.

Palabras clave: Patrimonio Mundial; Megalitismo; Menga; Viera; El Romeral; Península ibérica.

Key words: World Heritage; Megalithism; Menga; Viera; El Romeral; Iberian peninsula.

\section{INTRODUCCIÓN}

Los dólmenes de Antequera están enclavados en el norte de la provincia de Málaga, entre el valle del Guadalquivir y la cordillera bética (Fig. 1). Este gran sitio megalítico ha despertado un excepcional interés científico, académico y público desde que Rafael Mitjana y Ardison (1847) publicara un breve resumen de sus excavaciones en el dolmen de Menga. Durante el siglo XIX, la considerable celebridad de Menga le convertíría en un referente para el estudio de la monumentalidad prehistórica a nivel nacional e internacional (p. ej. referencias en Tenison 1853; Rojas 1861, 1874, 1879; Hancock 1882; Harlé 1887 y una excelente síntesis en Sánchez-Cuenca 2011). En 1886, el gran dolmen fue el primer sitio prehistórico español en lograr la declaración de Monumento Nacional, anticipándose en varias décadas a la cueva de Altamira.

El descubrimiento del dolmen de Viera y el tholos de El Romeral a comienzos del siglo XX aumen-

* Este trabajo es resultado del Proyecto "Biografías megalíticas: el paisaje monumental de Antequera en su contexto temporal y espacial" (HAR2017-87481-P, 2018-2021), Plan Nacional de I + D, Ministerio de Economía y Competitividad, Gobierno de España.

a Grupo de Investigación ATLAS (HUM-694). Dpto. de Prehistoria y Arqueología. Universidad de Sevilla. C/ María de Padilla s/n. 41004 Sevilla. España. Correo e.: coronada_mora@us.es https://orcid.org/0000-0002-5062-2604; LGS correo e.: lgarcia@us.es https://orcid.org/0000-0002-8404-9252 Recibido 8-V-2020; aceptado 5-VI-2020.

Copyright: (C) 2020 CSIC. Este es un artículo de acceso abierto distribuido bajo los términos de la licencia de uso y distribución "Creative Commons Reconocimiento 4.0 Internacional" (CC BY 4.0) 


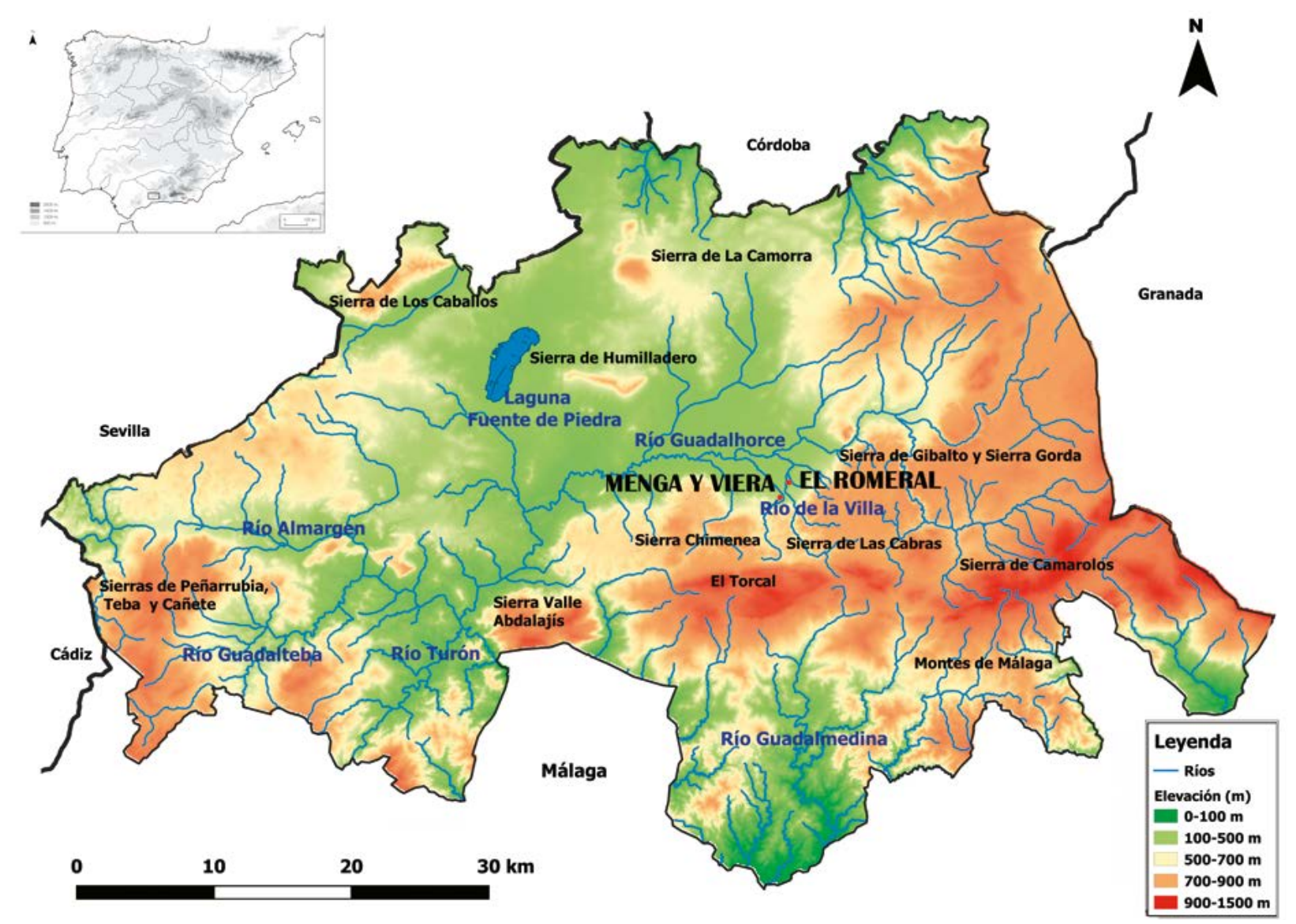

Fig. 1. Ubicación de los dólmenes de Menga, Viera y El Romeral en la península ibérica y en la provincia de Málaga (diseño Manuel Eleazar Costa Caramé, a partir de cobertura de altimetría del Instituto Geográfico Nacional, en color en la edición electrónica).

tó el interés por el conjunto megalítico antequerano, lo cual se reflejó en la rápida sucesión de publicaciones en sus primeras décadas (Gómez-Moreno 1905; Velázquez 1905; Mergelina 1922; Leisner y Leisner 1943, entre otros). En la década de 1940 se hicieron las primeras grandes intervenciones de restauración y musealización in situ de los tres monumentos (Giménez Reyna 1946), pero las investigaciones arqueológicas escasearon en la segunda mitad de la centuria.

A partir de finales de los 1980, la configuración en España de un nuevo sistema descentralizado de gestión patrimonial, y la asunción de las competencias en materia de Patrimonio Histórico por parte de la Junta de Andalucía intensificaron notablemente las intervenciones de todo tipo, incluyendo sucesivos proyectos de investigación dirigidos desde las universidades de Málaga (1986-1995), Granada (2005-2006) y Sevilla (2013-2021). La revisión que aquí presentamos forma parte de las investigaciones que esta última viene desarrollando desde 2013. En los últimos años se han logrado avances importantes en dos ámbitos del estudio del sitio antequerano hasta hace poco casi desconocidos: su dimensión territorial y paisajística (p. ej. García Sanjuán 2009; García Sanjuán y Wheatley 2009; García Sanjuán et al. 2015, 2021; Díaz-Guardamino et al. 2020) y sus complejas biografías (García Sanjuán y Lozano Rodríguez 2016; Bueno Ramírez et al. 2013b, 2017; García Sanjuán y Mora Molina 2018; García Sanjuán et al. 2019, etc. $\left.{ }^{1}\right)$. Estos progresos, y la ampliación del marco epistemológico de investigación y de gestión del sitio que implican, fueron de gran importancia para su inclusión en la Lista de Patrimonio Mundial de UNESCO en julio de 2016.

La citada inclusión por UNESCO supuso la culminación de un largo proceso, hasta cierto punto iniciado por Mitjana y Ardison, y a la vez abrió una etapa nueva en la que la investigación y gestión patrimonial

${ }^{1}$ C. Mora Molina, "Los monumentos megalíticos de Antequera (Málaga): una aproximación biográfica". Tesis Doctoral Inédita. Universidad de Sevilla, 2019. 
del sitio deben venir presididas por criterios técnicos de la mayor exigencia, encaminados a lograr una tutela integral de excelencia. Creemos de gran importancia abrir esta nueva etapa con una reflexión crítica sobre la trayectoria de actuaciones realizadas, valorando sus aciertos y errores. A partir de esta reflexión se podrá ofrecer una visión propositiva de cara a su futuro, tanto desde el punto de vista de la investigación científica, como de las actuaciones orientadas a su mejor conservación y difusión pública, valorando sus efectos recíprocos.

Nuestra revisión se basa en el análisis de una ingente cantidad de documentos inéditos (sobre todo proyectos e informes de las actuaciones) y numerosas publicaciones disponibles en la actualidad. De especial interés han resultado los planos y las fotografías que recogen de manera gráfica el estado de los monumentos a lo largo del tiempo. La valoración de esta documentación es esencial para conocer las múltiples transformaciones y modificaciones que los mismos han experimentado en los últimos dos siglos. Entender el impacto y las consecuencias de las intervenciones en las arquitecturas megalíticas es básica para su conservación y conocimiento futuros.

La imagen que ofrecen actualmente los monumentos no solo es resultado del genio creativo de las comunidades neolíticas y calcolíticas de Tierras de Antequera y de las sucesivas reutilizaciones que han conocido durante los últimos seis mil años, un tema que venimos investigando desde hace una década, sino que es también producto, en muy gran medida, como expondremos, de las decisiones tomadas por quienes han asumido la responsabilidad de su estudio y manejo como bienes culturales en los últimos doscientos años, y muy especialmente en las últimas cuatro décadas.

En este sentido, consideramos muy importante diferenciar entre las actividades arqueológicas que han conllevado una transformación material de los dólmenes de Antequera, de aquellas que no lo han hecho. Nos centramos en las de naturaleza intrínsecamente destructiva, como la excavación, que generan un nuevo episodio (a menudo irreversible) dentro de la biografía del monumento, o del sitio, dejando de lado actividades no destructivas, numerosas entre 1985 y 2019, como prospecciones de superficie y geofísicas, estudios de materiales arqueológicos, análisis científicos, etc.

El organismo que tiene encomendada la responsabilidad administrativa de la gestión del sitio (Conjunto Arqueológico de los Dólmenes de Antequera, CADA) no ha publicado hasta la fecha la correspondiente, y muy necesaria, nomenclatura oficial de los elementos constructivos principales de los tres monumentos (incluyendo ortostatos, cobijas, pilares y jam- bas), por lo cual usaremos la que venimos aplicando nosotros mismos (García Sanjuán y Mora Molina 2018; García Sanjuán et al. 2019, etc.) (Fig. 2).

\section{MENGA}

La primera alusión al dolmen de Menga aparece en una licencia ordinaria de 1530 concedida por César de Riarío, Obispo de Málaga, y Bernardino de Contreras, su Provisor y Vicario General, al clérigo presbítero Francisco Gavilán para la construcción de una ermita en honor a Nuestra Señora de Belén. Menga, denominada antrum, se cita por estar a unos $750 \mathrm{~m}$ del sitio designado para la construcción, el actual Convento de Belén. La primera obra que menciona la cueva de Menga es Discursos Históricos de Antequera de 1587 (Rallo Gruss 2005). En el siglo XVII, el dolmen fue descrito o mencionado en cinco obras originales, tres de ellas inéditas y otras dos publicadas, y en siete copias inéditas posteriores. Salvo en dos de ellas, se indicaba que la altura en el interior del monumento era de dos varas $(1,66 \mathrm{~m})$. Esta sugerencia de que el espacio interno del dolmen estaba parcialmente colmatado se repetiría a principios del siglo $\mathrm{XIX}^{2}$.

En efecto, cuando Mitjana lo excavó en una fecha imprecisa entre 1842 y 1847, el interior del dolmen estaba en parte colmatado por un relleno de piedras y tierra. El túmulo externo alcanzaba la altura de los ortostatos, pero no cubría las tres primeras cobijas (C1, C-2 y C-3) (Mitjana 1847: 5, 17-18). El vaciado de ese relleno aumentó la altura del espacio interior algo más de $1 \mathrm{~m}$, hasta alcanzar los 2,7-2,8 m (Mitjana 1847: 5-6, 17), dejando visible el tercio inferior de ortostatos y pilares. Después intervendria en el centro de la cámara, bajo la última cobija (C-5). Allí descubrió el pozo que se halla en el interior del dolmen, vaciando también su relleno hasta una profundidad que hemos estimado entre -5,4 y -7,02 m (discusión en García Sanjuán et al. 2018). Mitjana y Ardison (1847: 19) rompió también la losa de cabecera mediante la apertura de un orificio rectangular de entre 1,2-1,5 m de lado (Tenison 1853: 276), a partir del cual excavó una zanja en el sector oeste de la estructura tumular (Mitjana 1847: 19). Estas actuaciones cambiaron la apariencia interior y exterior de Menga, no sólo por la apertura de un nuevo acceso al interior del monumento en el sector de la cabecera, sino también por la presumible acumulación de la masa tumular extraída en otra zona del túmulo. Al finalizar los trabajos dispuso una verja a la entrada del monumento (Mitjana 1847: 6). Paradójicamente, ello no impediría el acceso

2 Véase nota 1. 


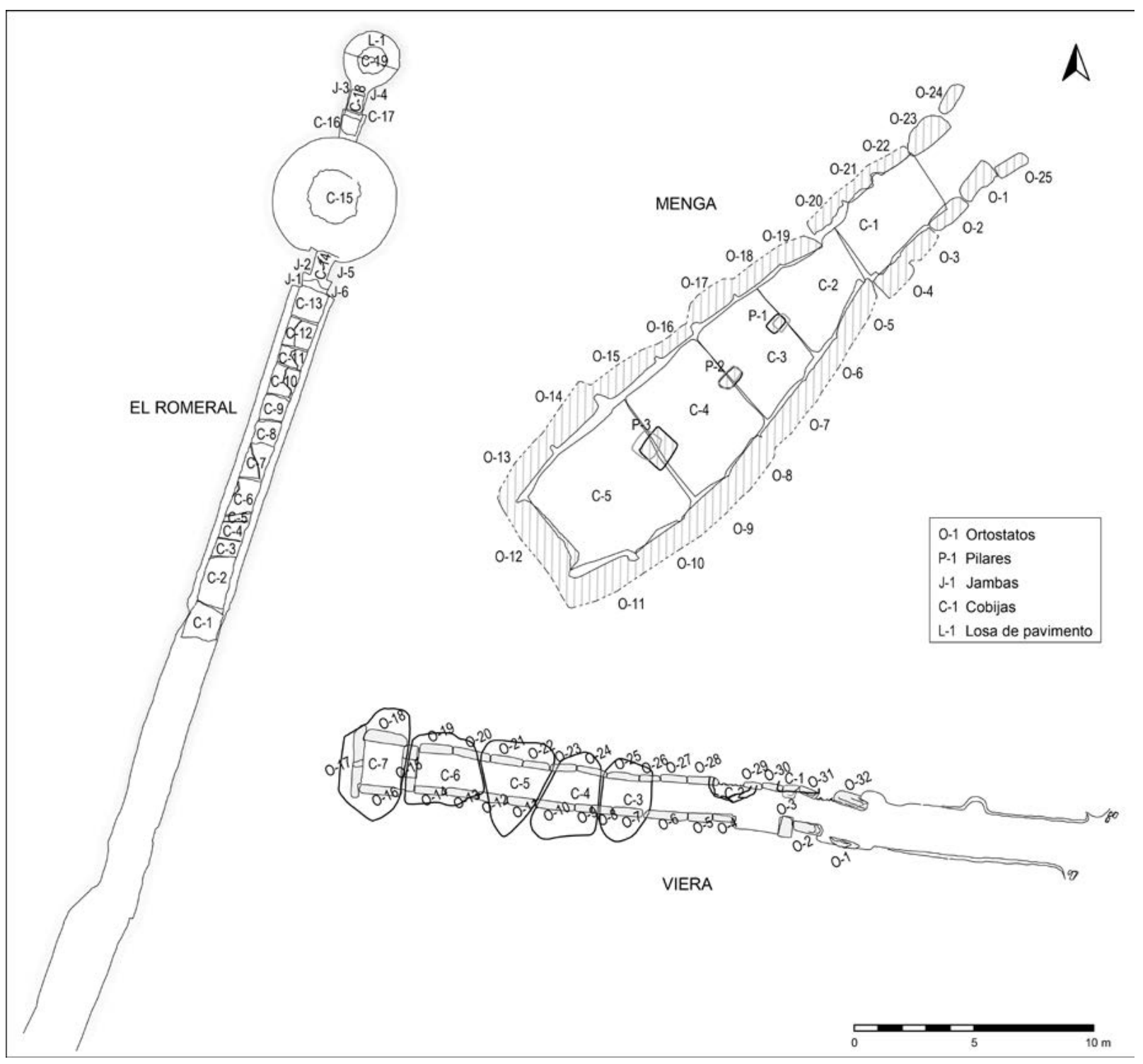

Fig. 2. Plantas de los dólmenes de Menga y Viera y el tholos de El Romeral (Antequera, Málaga) (diseño Coronada Mora Molina).

al interior, puesto que la descripción hecha por Tenison, tres años después de que Mitjana publicase su informe, sugiere que el orificio hecho en la losa de cabecera permanecía abierto. En todo caso, para 1861 esta verja ya había desaparecido (Rojas 1861: 295).

Entre la excavación de Mitjana y Ardison y 1900 la arquitectura y entorno del monumento sufrió actuaciones incontroladas y no registradas, pero resumibles en cuatro aspectos. El vaciado de su relleno hizo que la altura interior del monumento alcanzase los $3 \mathrm{~m}$ (Tenison 1853: 274; Hancock 1882: 68; Harlé 1887: 80), o incluso más, llegando hasta los actuales $3,45 \mathrm{~m}$ (Rojas 1879: 21). La cancela de protección de Mitjana y Ardison había desaparecido antes de 1861 (Rojas 1861: 295). La cubrición tumular de las cobijas había variado ligeramente. La primera $(\mathrm{C}-1)$ no estaba cubierta por el túmulo, la segunda (C-2) estaba casi completamente descubierta, y en algunos puntos de las otras tres (C-3 a C-5) se veía su superficie externa (Harlé 1887: 81). Por último, el pozo volvió a colmatarse, no quedando registrado en el croquis que del dolmen haría Manuel Gómez-Moreno en 1868 (García Sanjuán et al. 2018: 340). Trinidad de Rojas (1874: 58, 1879: 25) lo mencionó dos veces, probablemente, a partir de su publicación de 1861 . Incluso si el pozo hubiera continuado abierto entonces, en la segunda 
mitad de la década de 1870 ya no sería visible: no se vuelve a mencionar hasta su redescubrimiento en 2005.

El dolmen de Menga fue declarado Monumento Nacional mediante Real Orden de 1 de junio de 1886. En los meses siguientes el Estado tramitó la compra a su propietario, Manuel Zarco del Valle y Espinosa de los Monteros. El contrato se inscribió en el Registro de la Propiedad de Antequera el 4 de agosto de 1886 (Ruiz González 2011: 21-22).

En 1904, Mariano de Mazas realizó una nueva intervención en Menga sobre la que no se dispone de información. Debió abrir un hoyo, al menos de 0,50 $\mathrm{m}$, "en el rincón de la derecha del fondo", donde se localizó un hacha (Obermaier 1919: 27-28). Entre 1921 y 1922, Cayetano de Mergelina y Juan Cabré hicieron una nueva excavación, consistente en el vaciado parcial de las zanjas y alveolos de cimentación de ortostatos y pilares (Mergelina 1922: Lam. IIIb y V), localizando una segunda hacha junto al primer ortostato del lateral izquierdo de la cámara (Mergelina 1922: 85-86). Estos vaciados debieron ser rellenados entre 1922 y 1933, ya que así aparecen en las fotografías del interior del monumento que hicieron Georg y Vera Leisner durante su visita en febrero de 1933 o 1934 (Leisner y Leisner 1943, lam. 104.1, 104.2 y 105.2). Mergelina (1922: 77) apuntó que había tapiado "el enorme boquete de la cabecera" abierto por Mitjana y Ardison 80 años antes. Sin embargo, a principios de los 1930 los Leisner aún lo encontraron abierto (Leisner y Leisner 1943: 178), lo que coincide con la descripción de Giménez Reyna (1946) (vide infra). La zanja que Mitjana y Ardison (1847: 19) abrió al exterior, en el túmulo tras la losa de cabecera, continuaba abierta a esta altura, según consta en las plantas y secciones del monumento de varios autores (Gómez-Moreno 1905: 83; Obermaier 1919: 27; Mergelina 1922, lám. IV; Leisner y Leisner 1943, lám. 56) y en sus descripciones (Mortillet 1921; Hemp 1934; Leisner y Leisner 1943).

Varios autores indicaron que la primera, la segunda y la última cobija (C-1, C-2 y C-5) estaban parcialmente descubiertas (Amador de los Ríos [c.a. 1907]: 32; Hemp 1934: 407; Leisner y Leisner 1943: 178), es decir, que la cubrición tumular sobre estas losas era mínima. Todas las cobijas asomaban en la parte superior del túmulo, según Paris (1921: 10), una apreciación similar a las de Mitjana y Ardison (1847) y Harlé (1887) en la segunda mitad del siglo XIX. El túmulo tendría, al menos desde mediados del siglo XIX, muy poca potencia estratigráfica sobre las cobijas. Esto parece coherente con lo descubierto en la excavación del equipo de la Universidad de Málaga (UMA en adelante) en 1991 (Ferrer Palma 1997a), que dejó al descubierto el trasdosado de varios ortostatos y los laterales de varias cobijas. En el ortostato $8(\mathrm{O}-8)$ y la cobija 4 (C-4), según una fotografía publicada ese año, la potencia del relleno de tierra que recubría C- 4 variaba entre $20 \mathrm{~cm}$ y 50 $\mathrm{cm}$, pudiendo corresponder los últimos $10 \mathrm{~cm}$ al sedimento aportado en la restauración de 1940-1941 (AA. VV. 1993: 43).

En 1913 se colocó una nueva verja a la entrada del dolmen (Mortillet 1921: 476) que debió desaparecer a los pocos años, pues en 1922 se dispuso una tercera (Mergelina 1922: 77). Al comparar la fotografía del acceso a Menga tomada por Juan Becerra en 1896 con las publicadas entre 1905 y 1943 (Fig. 3), en las segundas aparece un camino que corta fundamentalmente el lateral izquierdo o sureste del túmulo y que no se distingue en la primera. El camino se abriría entre 1896 y 1905 rompiendo, al menos, el borde sureste del túmulo y la entrada que entonces presentaba el monumento. La fotografía de Leisner y Leisner (1943, lám. 98.4), tomada en 1933 o 1934 (Fig. 3), muestra otro cambio destacado: un murete de mampostería en el lateral sureste del túmulo. A fecha de hoy se desconoce si ese murete fue construido entre 1921 y 1933 , o es una estructura más antigua.

Entre 1940 y 1941 se produjo la primera gran actuación de restauración y puesta en valor de los megalitos antequeranos, incluyendo una intervención integral para posibilitar su acceso y visita en tanto que destacados monumentos nacionales. La Junta de Defensa del Patrimonio Artístico Nacional y la Delegación de Zona de Bellas Artes financiaron con un presupuesto de 3.000 y 2.000 pesetas las actuaciones en Menga y Viera, dirigidas por Francisco Prieto-Moreno y Pardo, arquitecto de Zona de Bellas Artes, y supervisadas por Simeón Giménez Reyna (1946: 37-43 y lám. XIII-XVII), Comisario Provincial de Excavaciones Arqueológicas.

En aquellos años el túmulo de Menga tenía grandes hoyos (probable resultado de los buscadores de tesoros a los que Trinidad de Rojas ya había hecho referencia) y seguía abierta la zanja de Mitjana y Ardison en el trasdosado de la losa de cabecera. El interior estaba sucio, al menos con $60 \mathrm{~cm}$ de relleno respecto al suelo 'original', y muy deteriorado por filtraciones de agua (que alcanzaban el interior desde la cubierta). Continuaba abierto el hueco que Mitjana y Ardison hizo en el lateral derecho de la losa de cabecera. Se había fracturado también el ortostato 14 (O-14), desprendiéndose una lasca que sujetaba un puntal de madera apoyado en el pilar 3 (P-3), y los pilares 1 y 2 (P-1 y P-2) presentaban importantes pérdidas de materialidad en su tercio inferior (Giménez Reyna 1946: 38). En estos años parece que Menga fue utilizado como vivienda por "una tribu de gitanos" (Giménez Reyna 1946: 37), presumiblemente desalojada antes de iniciarse la restauración. 
A

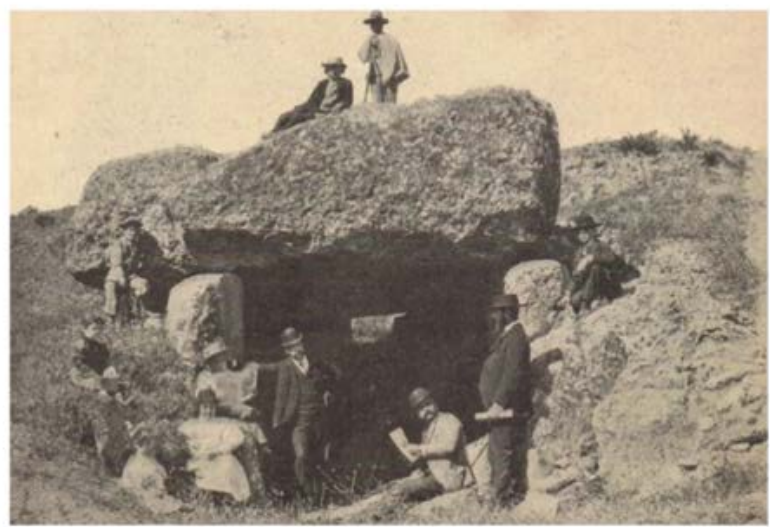

C

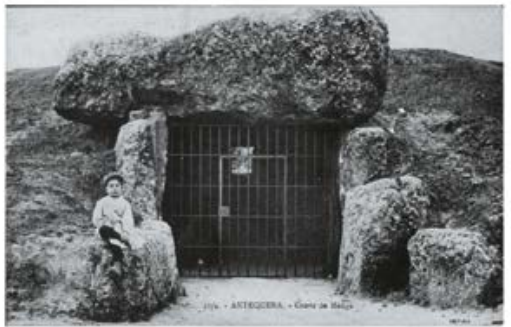

F

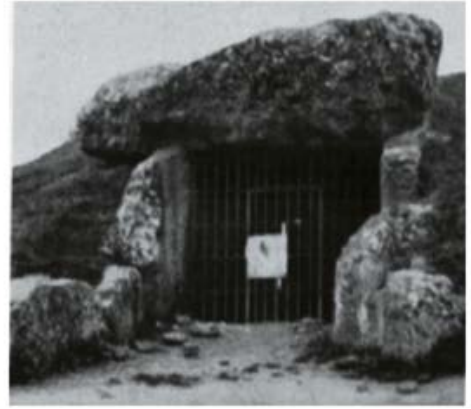

D

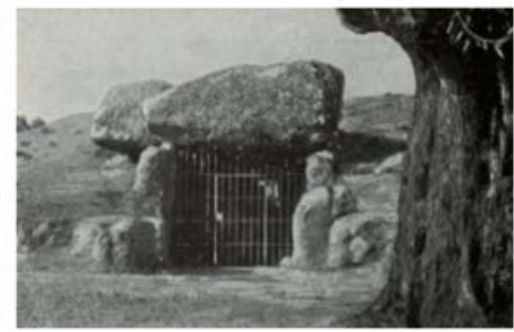

G

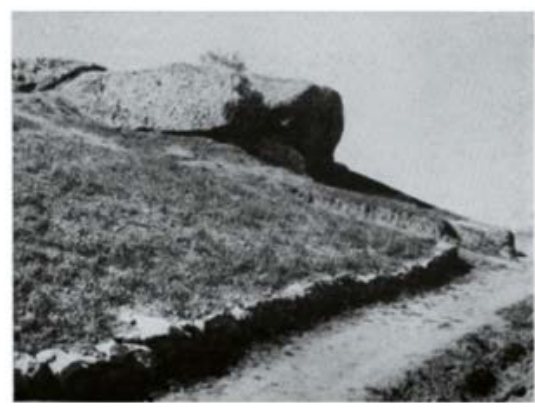

B

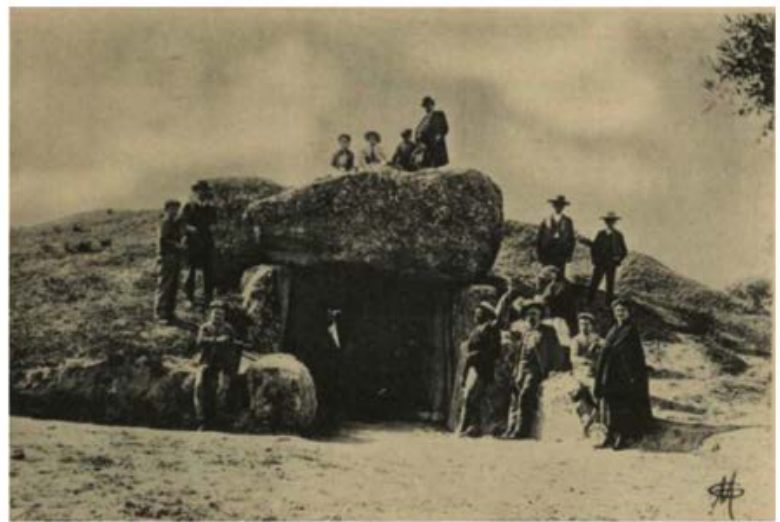

E

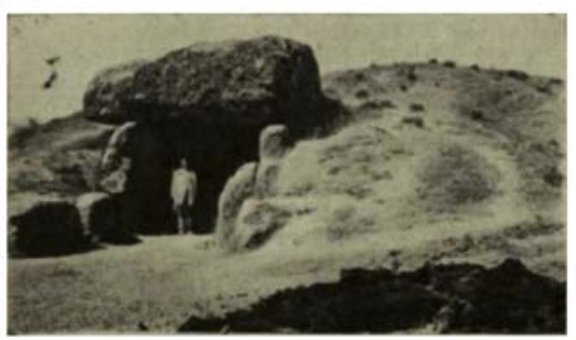

$\mathrm{H}$

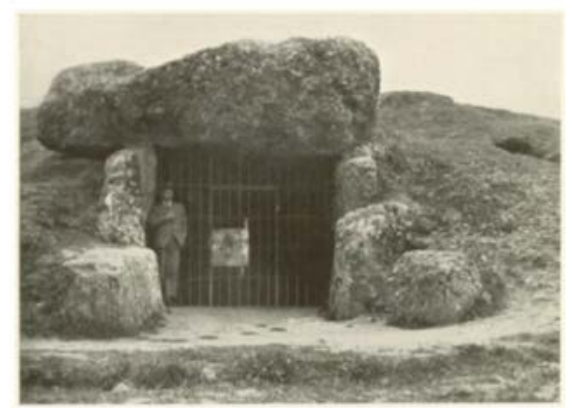

Fig. 3. Fotografías de la entrada del dolmen de Menga (Antequera, Málaga): A. 1896 (Barrera 1896: 1); B. circa 1905 (Gómez-Moreno Martínez 1905: 133); C. 1913 (Mortillet 1921: 476); D. circa 1921 (Paris 1921: lám. 3); E. circa 1921-1922 (Mergelina 1922: lám. 3); F. y G. 1933 (Leisner y Leisner 1943: lám. 105.1 y 98.4); H. 1934 (Hemp 1934: lám. 53.2).

Los trabajos en el interior del dolmen consistieron en: i) la reparación de la cancela de entrada; ii) el tapado del hueco abierto de la losa de cabecera; iii) la reposición de la lasca desprendida del O-14, fijada con cemento y sujetada con grapas al resto del ortostato; y iv) el recrecido del tercio inferior de los pilares mediante la disposición de una capa de cemento aislante (Giménez Reyna 1946: 38). En el túmulo se centraron en: i) tapar los hoyos y el hueco abierto tras el lateral derecho de la losa de cabecera; ii) disponer una capa de arcilla impermeable por toda su extensión; iii) ensancharlo "a su debido diámetro, que los labradores vecinos habían ido menguando"; y iv) abrir unas cunetas de desagüe a su alrededor (Giménez Reyna 1946: 38).

Para favorecer y facilitar su visita se dispuso a la entrada un poste indicativo, y se construyeron un camino para coches desde la carretera Antequera-Archidona hasta el dolmen y una plazoleta delante del monumento, delimitándose ambos elementos con cipreses y flores (Giménez Reyna 1946: 38-39), así como un camino hacia el dolmen de Viera que discurría por el lateral noroeste del túmulo (Giménez Reyna 1946: 43 y Lam. XVIII).

En 1966, el Ayuntamiento de Antequera compró las tres parcelas en las que se ubican Menga y Viera, 
todas plantadas de olivos viejos ${ }^{3}$. Posiblemente a partir de este momento se delimitaría físicamente el conjunto Menga-Viera mediante su vallado. En 1967, se ejecutaron nuevas "obras de urbanización" en el entorno de ambos dólmenes. Por acuerdo entre el Director General de Bellas Artes y el alcalde de Antequera, tras la adquisición de los terrenos por parte del Ayuntamiento, los futuros trabajos de "urbanización, accesos y embellecimiento de la zona en la que están enclavadas las cuevas prehistóricas" serían asumidos por la Dirección General ${ }^{4}$. Para ello, el Arquitecto Conservador de los Monumentos de la 7. ${ }^{\mathrm{a}}$ Zona, Francisco Prieto-Moreno y Pardo, remitió al Comisario General la Memoria de obras de urbanización. En ella se planteaba: (i) reponer los cipreses a lo largo del camino de acceso a los dólmenes; (ii) pintar las cancelas y los carteles; (iii) limpiar las cunetas construidas en 1941 para mejorar la evacuación de agua de lluvia; (iv) reforzar los pavimentos empedrados mediante la disposición de una nueva capa de mortero; (v) eliminar los arbustos de los muretes de mampostería construido en Menga entre 1921 y 1933 y en Viera en 1941 a ambos lados de los accesos a los monumentos y su recrecido en unos $50 \mathrm{~cm}$ para impedir el desprendimiento de tierra procedente del túmulo ${ }^{5}$. El Archivo Central del Ministerio de Cultura transfirió ya los expedientes sobre dichas obras al Archivo General de la Administración de Alcalá de Henares (Ruiz González 2011: 35). Los únicos datos publicados sobre esta intervención apun$\tan$ que "recientemente el Ayuntamiento de Antequera ha reparado el camino de acceso y cuida su vigilancia" (Giménez Reyna 1968: 28).

En 1983-1984 se reanudaron las intervenciones en el entorno de Menga y Viera (Haro Ruiz 1990: 95). Las fotografías aéreas del Vuelo Interministerial de 1973-1986, el Vuelo Nacional de 1980-1986 y las tomadas en 1987 por Paisajes Españoles S.A. demuestran que este proyecto debió ejecutarse casi en su totalidad. Se abrió la entrada del lateral suroeste del conjunto, el camino que discurre desde dicho lateral hacia Viera, de $110 \mathrm{~m}$ de longitud y $6 \mathrm{~m}$ de anchura, la plaza central y el camino hacia Menga por el lateral noroeste de su túmulo, decorándose el recorrido con plantaciones de jardinería. También en este momento se hizo la primera ampliación longitudinal hacia el este del corredor de Viera, que quedó con una longitud de 9

\footnotetext{
3 Actas Capitulares, Sesión 19 de abril, Archivo Histórico Municipal de Antequera, libro 2210, folio 78 .

${ }^{4}$ Actas Capitulares, Sesión 1 de marzo de 1966, Archivo Histórico Municipal de Antequera, libro 2116, folio 58.

5 F. Prieto-Moreno y Pardo, "Memoria de obras de urbanización en los alrededores de las Cuevas de Menga y Viera. Antequera (Málaga)". Ministerio de Educación y Ciencia. Conservación de Monumentos de la 7. Zona, mayo, 1967. C/70.835.
}

$\mathrm{m}$ en el lateral norte y $8 \mathrm{~m}$ en el lateral sur. Se modificó por completo el acceso al mismo y se amplió su diámetro a $50 \mathrm{~m}$ en el eje este-oeste.

A partir de 1984 se transfirieron las competencias en materia de cultura desde el Estado a la Junta de Andalucía, quien las asumió y desarrolló a través de las Delegaciones Provinciales ${ }^{6}$. El cambio de las figuras de protección de los bienes patrimoniales por la Disposición Adicional Primera de la Ley de Patrimonio Histórico Español 13/1985 inició una etapa totalmente nueva en la gestión de los dólmenes de Antequera. Administrativamente pasaron a ser Bienes de Interés Cultural, conformando en 1986 una Unidad Administrativa dependiente de la Consejería de Cultura $^{7}$, aunque el personal no se incorporaría de forma efectiva a dicha Unidad Administrativa hasta 2004. Los tres monumentos pasaron a ser propiedad del Estado.

Con el cambio del contexto administrativo, la Dirección General de Bienes Culturales de la Junta de Andalucía encargó a los arquitectos Enrique Haro Ruiz y Manuel Salado Ordoñez un "Proyecto de Ordenación General del Recinto Primero del Conjunto Arqueológico Dólmenes de Antequera", que sería aprobado en 1990 (Ruiz González 2011: 38-41 y 150). El proyecto diseñado contemplaba por un lado el "estudio arqueológico, restauración y limpieza de los monumentos", y por otro "la restauración y la construcción del paisaje en torno a los monumentos" (Haro Ruiz 1990: 95). Esta actuación se haría en estrecha colaboración con la UMA, que desde 1986 había iniciado el Proyecto General de Investigación (PGI) "Reconstrucción Arquitectónica y Paleoambiental en la Necrópolis Megalítica de Antequera" con el patrocinio y la financiación de la Consejería de Cultura de la Junta de Andalucía. Estas actuaciones perseguían dos objetivos fundamentales. El primero era el estudio arquitectónico de los monumentos, incluyendo informes geológicos y excavaciones en el interior, en los túmulos y en su entorno, a cargo de un equipo dirigido por los profesores José Enrique Ferrer Palma e Ignacio Marqués Merelo (Ferrer Palma 1997a, 1997b). El segundo era la restauración y limpieza de los monumentos, siguiendo las indicaciones que fueran formuladas por el equipo de arqueólogos de la UMA, y la eliminación de los caminos rodados al interior del conjunto y de la vegetación plantada en la intervención de 1983-1984 (Haro Ruiz 1990: 95), trabajos que finalmente no se llevaron a cabo.

\footnotetext{
${ }^{6}$ Rel Decreto 864/1984, de 29 de febrero, BOE 113 de 11 de mayo de 1984 y Real Decreto 1124/1984, de 29 de febrero BOE 143 de 15 de junio de 1984.

7 Decreto 395/1986, de 17 de diciembre, BOJA 115 de 26 de diciembre de 1986.
} 
Las actuaciones arqueológicas comprendieron prospecciones arqueológicas desarrolladas en un radio de $5 \mathrm{~km}$ con centro en Menga y Viera (Marqués Merelo et al. 2004b: 180) en 1986 (eje este-oeste) y 1988 (eje norte-sur), que localizaron varios yacimientos (Ferrer Palma 1997a: 131, 136). Además, se efectuaron excavaciones arqueológicas en Menga y Viera, consistentes en 58 cortes arqueológicos (Ferrer Palma 1997b; Ferrer Palma et al. 2004; Marqués Merelo et al. 2004b). Se tapó la galería que discurre por el trasdosado de la losa de cabecera y los ortostatos del lateral norte de Viera en 1988, mediante la reconstrucción de la masa tumular (Ferrer Palma 1997a: 134). Por último, se tomaron muestras para estudio palinológico en los cortes abiertos en los túmulos de Menga y Viera (Ferrer Palma 1997a, 1997b). En el marco del citado PGI, aunque de manera diferenciada del resto de actuaciones arqueológicas, Rafael Atencia Páez dirigió en 1988 una excavación destinada a documentar la actividad de Edad Antigua en el entorno de los monumentos. Se abrieron 10 cortes, 3 en la ladera noreste donde se erige Menga ( 8 x 1,5 m: 2 con ampliaciones de 2 x $1,5 \mathrm{~m}$ en su lateral norte hacia el oeste) (Anexo 1) y 7 (6 x $6 \mathrm{~m})$ en el lateral sur del recinto de los dólmenes, entre Viera y la carretera Antequera-Archidona (Anexo 2). Los resultados de esta intervención permanecieron inéditos hasta su publicación parcial, basada en el archivo fotográfico disponible y los materiales conservados en el Museo de Málaga (Aranda Jiménez et al. 2015).

La UMA abrió en Menga 33 cortes de excavación: 6 en 1986,11 en 1988 y 16 en 1986. Se localizaron 10 en el trasdosado de los ortostatos, 20 en otras zonas del túmulo y del entorno del dolmen, 2 en el atrio y 1 en el interior, cuyos límites fueron sobrepasados, excavándose amplias zonas del interior del monumento (Ferrer Palma et al. 2004: 186; Marqués Merelo et al. 2004b: 180) (Anexo 1). La gran cantidad de cortes excavados en el túmulo de este dolmen (como en el de Viera) y su ulterior cubrición solo con placas de fibrocemento afectaron negativamente a su estado de conservación, pues los cortes permanecieron abiertos varios años, apareciendo humedades por filtración. En 1995, tras la última campaña de excavación (en Viera), se rellenaron con tierra, aunque los problemas de filtración de agua de lluvia habrían de continuar.

Ya en 1997 hubo una actuación de emergencia en Menga y en Viera, dirigida por Pedro Lobato Vida ${ }^{8}$. Como resultado de la misma, en primer lugar se impermeabilizaron ambos túmulos, rellenándose los socavones existentes en las catas abiertas por el equipo

\footnotetext{
${ }^{8}$ P. Lobato Vida, "Conjunto Dolménico de Antequera, Málaga. Informe Complementario Emergencia Dólmenes de Menga y Viera". Informe inédito. Delegación Provincial de Cultura de Málaga, 1997.
}

de la UMA con una capa de $40 \mathrm{~cm}$ de albero mejorado con cal, compactado manualmente, y mediante una capa continua de albero enriquecido con cal de unos $15 \mathrm{~cm}$. En segundo lugar, se instaló un nuevo sistema de drenaje en el corredor de Viera. Por último, se dispuso un nuevo suelo con pendiente ascendente hacia el interior, consistente en una capa de albero compactado, para evitar la entrada y la acumulación de agua en el interior de la estructura ortostática. Estos trabajos provocaron una importante alteración en la forma del túmulo, recrecido unos $15-20 \mathrm{~cm}$ tras el rellenado de las catas y la disposición de la capa de albero.

El problema de la filtración de agua en el interior de Menga persistió. En 1999 un nuevo proyecto de impermeabilización, poco agresivo, dispuso una película de polietileno sobre el túmulo del dolmen y una nueva capa de albero y cal de cubrición. En 2001 una tercera intervención en el túmulo de $\mathrm{Menga}^{9}$ intentó atajar el persistente problema de la entrada de agua de lluvia al interior. La empresa de construcción Hermanos Campano S.L. ejecutó la actuación centrada en el sector noreste-norte del túmulo. Ello tuvo un gran impacto sobre la apariencia exterior del monumento, al construirse una estructura aterrazada de lajas, morteros de cal y mallas de fibra de vidrio en el lateral noreste del túmulo para contener los rellenos de tierra que se dispusieron seguidamente en su cuadrante noreste-norte.

Entre 2001 y 2002 la empresa de restauración Crest Arte S.L. intervino en los ortostatos, cobijas y pilares Menga. Esta actuación, que implicó la restitución volumétrica de los soportes pétreos, pudo ocasionar importantes desperfectos al implicar la eliminación de los materiales añadidos en restauraciones anteriores y de los grafitis que contenían los soportes, así como la limpieza de todos los elementos pétreos. Esta serie de actuaciones, calificadas posteriormente de "impactantes" (Carrera Ramírez 2009: 235), ya estaban planteadas en el proyecto de "consolidación" de Menga redactado en 1997 y desestimado por la Junta de Andalucía por su excesiva agresividad. Las dos últimas grandes actuaciones arqueológicas en el dolmen de Menga, efectuadas entre 2005 y 2006, implicaron nuevos cortes arqueológicos y excavaciones en el interior, en el túmulo y en el entorno inmediato del monumento.

En la primavera de 2005, Verónica Navarrete Pendón dirigió el "Proyecto de Actividad Arqueológica Preventiva del tipo Seguimiento Arqueológico de la Obra de adecuación del pavimento, iluminación y accesos para minusválidos al sepulcro megalítico de

\footnotetext{
9 I. Baceiredo Rodríguez, "Memoria Final de las Actuaciones en el Dolmen de Menga, Antequera, Málaga". Memoria inédita. Delegación Provincial de Cultura de Málaga, 2002.
} 
Menga". En realidad, la actuación conllevó nuevas excavaciones en el interior y exterior del dolmen que incluyeron sectores y cortes ya excavados previamente por el equipo de la UMA en 1988 y 1991, y también cortes que fueron planteados y excavados ex novo. Recientemente se ha publicado una monografía de esta excavación con un amplio estudio del registro y de los materiales recuperados (Mora Molina et al. 2018: 59-62).

En octubre de 2005 se inició el proyecto "Intervención Arqueológica en el Conjunto Megalítico de Menga y Viera (Antequera, Málaga)", bajo la dirección de Francisco Carrión Méndez, de la Universidad de Granada, cuya ejecución se extendería hasta marzo de 2006. Este proyecto supuso un amplio estudio geoarqueológico de los tres monumentos antequeranos y su entorno, bajo la dirección de José Antonio Lozano Rodríguez, y nuevas excavaciones en el dolmen de Menga ${ }^{10}$. La excavación se materializó en tres cortes arqueológicos, ubicados en el sector noroeste (1), en el cuadrante suroeste del túmulo (2) y en el lateral norte del cerro (3) donde se erige el dolmen. En la actualidad está en preparación una monografía que recogerá los principles resultados de esta intervención.

Después de 2006 no ha habido intervenciones de importancia en el dolmen de Menga. En 2019 fue retirada la cancela de entrada al monumento, que había quedado obsoleta como dispositivo de protección desde que el recinto fuese completamente vallado y se articulasen medidas de vigilancia a partir de la declaración por parte de UNESCO en 2016.

\section{VIERA}

Las mismas obras de los siglos XVI y XVII que citan el dolmen de Menga mencionan de pasada otra "cueva" en sus inmediaciones, probablemente en referencia a Viera. Sin embargo, el monumento no sería explorado hasta principios de 1903 cuando lo descubriesen los hermanos José y Antonio Viera, de los que el dolmen tomaría su nombre. Lo publicado en las descripciones de la prensa del momento ${ }^{11}$ sugiere cómo se realizó la excavación y cómo se accedió al interior del megalito. La entrada al dolmen se encontraba oculta, por lo que los Viera excavaron una zanja en el túmulo para acceder al corredor y la cámara, que es-

\footnotetext{
${ }^{10}$ F. Carrión Méndez, T. Muñiz López, D. García González, J. A. Lozano Rodríguez, P. Feliz y C. F. López Rodríguez, "Intervención arqueológica en el Conjunto Megalítico de Menga y Viera (Antequera, Málaga)". Memoria inédita. Delegación Provincial de Cultura de Málaga, 2006.

${ }^{11}$ El Defensor de Granada, año XXV, n. ${ }^{\circ}$ 13.128: 1, Granada, 28 de octubre de 1093: "Desde Antequera". La Vanguardia, año XXIII, n. 8887: 2, Barcelona, 4 de noviembre de 1903: "Monumento druida".
}

taban parcialmente colmatados ${ }^{12}$. Es posible que la puerta perforada que separa ambos espacios (O-15) estuviera cegada. Se alcanzó, o se excavó, la galería que recorre el trasdosado de la losa de cabecera y el lateral derecho o norte del corredor. Es difícil precisar la fecha de apertura de esta galería, que permanecería abierta y transitable hasta 1988 (Ferrer Palma 1997a: 134): ello pudo ocurrir en la Antigüedad, el Medievo o la Edad Moderna y que los hermanos Viera la descubrieran, aunque tampoco es descartable que ellos mismos la excavaran. Si la galería fue abierta de antiguo, pudo permanecer transitable varios siglos sin que colapsara el edificio, ya que las cobijas sobrepasan la anchura de los soportes ortostáticos entre $0,45 \mathrm{~m}$ y $1,38 \mathrm{~m}$ desde el trasdosado de los ortostatos, apoyando sobre el encachado construido en torno a la estructura ortostática (Ferrer Palma et al. 2004: 206). Este solo estaba desmontado en parte por la excavación de la citada galería. Creemos que los hermanos Viera pudieron excavar la fosa abierta en la zona central del suelo de la cámara en 1903.

El interior de Viera fue excavado por completo, y para su cerramiento se colocó una puerta de madera (Amador de los Ríos [c.a. 1907]: 36) sin que, al parecer, entre la fecha de su excavación y 1933 se llevaran a cabo tareas de mantenimiento en su interior. Según Cayetano de Mergelina (1922: 81) la parte descubierta del corredor estaba colmatada por tierra procedente del exterior, algo que representa en su sección del monumento (Mergelina 1922: Lam. VIII). Ello sugiere que entre 1903 y 1922 el tramo de corredor descubierto se fue volviendo a colmatar poco a poco, llegando en 1922 casi a la misma altura que los ortostatos en ciertos tramos. Además, al menos desde esa fecha, la primera cobija conservada completa (C-4) se encontraba partida en dos (Mergelina 1922: Lam. VIII).

Viera fue declarado Monumento Nacional en 1923 sin que, al parecer, ello implicara a corto plazo una mejora en su estado de conservación. Cuando Georg y Vera Leisner visitaron el sitio y estudiaron los tres monumentos, en febrero de 1933 o 1934, hallaron en Viera un relleno sedimentario de unos $0,6-0,8 \mathrm{~m}$ de espesor en el tramo descubierto del corredor y derrumbados en el interior del mismo varios de los ortostatos, incluyendo, al menos, los O-27, O-28, O-29 y O-30 y la cobija C-2 (Leisner y Leisner 1943, lám. 106.2). El matrimonio alemán indicó también que, en ese momento, se estaba trabajando en una reconstrucción del corredor y en la estabilización del túmulo (Leisner y Leisner 1943: 182). Las actuaciones debieron comple-

${ }^{12}$ La Vanguardia, año XXIII, n. ${ }^{\circ}$ 8881: 4, Barcelona, 26 de octubre de 1903: "Monumento prehistórico". 
tarse entre 1933 y 1934, ya que el corredor aparece ya despejado y los ortostatos y la cobija derrumbados restituidos a su posición original en las fotografías publicadas por Hemp (1934, lám. LIV, 1-2).

A finales de los años 1930 el dolmen de Viera estaba sucio, pero sin grandes desperfectos, aunque la cobija C-4 seguía rota en dos y permanecían abiertos el orificio realizado en la losa de cabecera y la galería que discurría por el trasdosado de la cabecera y del lateral derecho del dolmen (Giménez Reyna 1946: 4041). Los trabajos ejecutados en 1941 bajo la dirección de Francisco Prieto-Moreno y Pardo y Simeón Giménez Reyna afectaron principalmente al túmulo, al acceso y al tramo de corredor descubierto. Después de eliminar la vegetación silvestre, el túmulo fue cubierto con una capa de arcilla para impermeabilizarlo, y se abrió una cuneta a su alrededor para facilitar la evacuación de las aguas de lluvia. En el acceso al interior del monumento se construyeron tres escalones para salvar el desnivel del exterior con el corredor. En el tramo descubierto del corredor se retiraron la vegetación, las piedras y la tierra que lo rellenaban parcialmente, despejándose el umbral de la segunda puerta perforada (O-3), se reconstruyeron las paredes de mampostería y se arregló la puerta que cerraba el paso al tramo cubierto del monumento (Giménez Reyna 1946: 43).

Durante las actuaciones llevadas a cabo en 19831984 en el entorno de Menga y Viera se hizo la primera ampliación longitudinal hacia el este del corredor de este último, $9 \mathrm{~m}$ en el lateral norte y $8 \mathrm{~m}$ en el lateral sur, modificándose por completo el acceso al mismo y ampliándose el diámetro del túmulo a los $50 \mathrm{~m}$ de diámetro en el eje este-oeste (Haro Ruiz 1990: 95).

En los años siguientes, como parte del PGI llevado a cabo por la UMA, ya mencionado anteriormente en relación con Menga, se excavaron en Viera 25 cortes ( 2 en 1986, 11 en 1988 y 12 en 1995): 2 en el atrio, 6 en el trasdosado de los ortostatos del lateral sur, 1 en el trasdosado del lateral norte y 16 en el túmulo y el entorno del monumento (Ferrer Palma et al. 2004: 186). También se excavó el suelo del espacio interior del dolmen (Ferrer Palma 1997b: 129-130) (Anexo 2) y Rafael Atencia Páez en la intervención ya mencionada de 1988 abrió 7 cortes (de 6 × 6 m) en el lateral sur del recinto de los dólmenes, entre Viera y la carretera Antequera-Archidona.

La situación de Viera tras acabar estas excavaciones reprodujo exactamente la de Menga. Los cortes permanecieron abiertos durante varios años, provocando problemas de inundación que amenazaron la estabilidad de la construcción. Una actuación de emergencia, encaminada a solventarlos, llevada a cabo en 1997, como en Menga, bajo la dirección de Pedro Lobato, produjo a su vez nuevas alteraciones en el monumento. La intervención consistió en excavar una zanja de drenaje y una arqueta de desagüe para la evacuación de aguas desde el tramo de corredor descubierto hacia el exterior del monumento, y en la disposición de un nuevo suelo, de albero compactado, con pendiente ascendente desde el acceso al interior del megalito. El resultado fue la rotura del firme original del dolmen y la del lateral izquierdo o sur del umbral de la primera puerta perforada (O-3). Para impermeabilizar el túmulo, además del rellenado de las catas, se dispuso una capa de albero y cal que elevó la altura del túmulo unos 15-20 cm. En Viera, al contrario que en Menga, esta actuación resultó ser efectiva para evitar la entrada de agua en el monumento.

En 2003-2004 se propuso de nuevo la consolidación y la restauración de Viera. La intervención también fue diseñada y ejecutada por un arquitecto, Antonio Villalón Conejo ${ }^{13}$, sin contar con un equipo de arqueólogos especializados en intervenciones de este tipo en monumentos megalíticos. Esta actuación buscaba atajar los daños que presentaban los ortostatos y las cobijas como consecuencia de las filtraciones de agua y las humedades a las que había estado sometido el monumento entre 1988 y 1997, antes del tapado definitivo de las catas del equipo de la UMA. Se proponía solucionar los daños estructurales del monumento, sobre todo las fracturas en las cobijas C-3 y C-4 (incluyéndose posteriormente la C-5), y los desplomes hacia el interior del monumento de los ortostatos O-23 a O-26. Ademas se intentaba subsanar deficiencias detectadas en el sistema de evacuación da aguas instalado en 1997, disponer un nuevo sistema de iluminación eléctrica y reparar la verja que cerraba el acceso al tramo cubierto del monumento.

Luis-Efrén Fernández Rodríguez dirigió el seguimiento arqueológico de los trabajos planteados en el proyecto de consolidación. La excavación supuso la apertura y el posterior rellenado de un corte de 7,3 m en el eje longitudinal del dolmen (este-oeste), 6,5 m en el eje transversal (norte-sur) y unos $3,5 \mathrm{~m}$ de profundidad sobre las cobijas C-3, C-4 y C-5, que profundizaba otros $2 \mathrm{~m}$ en el trasdosado de los ortostatos O-23 a O-26 del lateral norte (Fernández Rodríguez et al. 2006). Dicho sector estaba destruido en parte por la 'antigua' galería que recorría el trasdosado de los ortostatos del lateral norte.

Se abrieron tres series de zanjas en el túmulo, en su entorno y en el acceso al monumento: unas de drenaje conducirían el agua proveniente de la parte más alta del mismo hacia la acequia situada en el límite

${ }^{13}$ A. Villalón Conejo, "Proyecto de consolidación del dolmen de Viera. Conjunto Dolménico de Antequera. (Málaga)”. Proyecto inédito. Delegación Provincial de Cultura de Málaga, 2001. 
oeste del recinto y hacia la ladera este. Las dos restantes eran zanjas de cimentación. Unas zanjas de 17 $\mathrm{m}$ de longitud y $0,5 \mathrm{~m}$ de anchura se destinaban a unos nuevos muros de mampostería dispuestos en los laterales norte y sur del corredor de acceso. Este se prolongaba $8 \mathrm{~m}$ en el lateral norte y $9 \mathrm{~m}$ en el lateral sur, extensiones que se añadían a las realizadas en 19831984. Las otras zanjas, de $0,5 \mathrm{~m}$ de anchura y $0,5 \mathrm{~m}$ de profundidad, se abrieron entorno a los sectores noreste $(28 \mathrm{~m}$ de longitud) y sureste del túmulo $(40 \mathrm{~m}$ de longitud) para la construcción de muros de contención de los rellenos que iban a aumentar la altura del túmulo. El túmulo fue ampliado en altura y en diámetro en esta intervención. La altura se incrementó unos $0,5 \mathrm{~m}$, pasando de la cota máxima estimada para el túmulo de 504,20 $\mathrm{m}$ a la cota actual de 505,00 m. El diámetro pasó de los 43,40 m estimados por nosotros a los $52 \mathrm{~m}$ de longitud en el eje norte-sur y los $62 \mathrm{~m}$ en el eje este-oeste, que había sido ampliado ya en 1983-1984 hasta los $50 \mathrm{~m}$ de longitud.

Entre los cambios efectuados en la estructura ortostática destacan: (i) la reparación in situ de las cobijas C-3, C-4 y C-5, que fueron cosidas mediante resina epoxi y varillas de acero inoxidable corrugadas, y reforzadas con pletinas metálicas (Fernández Rodríguez et al. 2006: 96; Fernández Rodríguez 2009: 70$71)$; ii) la basculación de los ortostatos O-23 a O-26 a su posición vertical y su anclaje mediante varillas metálicas a estructuras de fábricas de ladrillos construidas en el trasdosado de los ortostatos (Fernández Rodríguez et al. 2006: 96; Fernández Rodríguez 2009: 71); (iii) el anclaje de las cobijas C-3 y C-4 a los ortostatos del lateral derecho o norte mediante elementos metálicos angulares y tacos químicos, amarrando la cobija C-3 a los ortostatos O-25 y O-26 y la cobija C-4 a los ortostatos O-23 y O-24; (iv) la posible disposición de una capa de cal y arcilla con lajas de piedra entre las cabezas de los ortostatos O-7 a O-10 y O-26 a O-23, tal y como se preveía en el Proyecto de Consolidación, para respetar el sistema constructivo original; (v) la probable limpieza de la cara interna de los ortostatos y cobijas; (vi) la restauración de los ortostatos O-26 y O-24, la losa de cabecera (O-17) y la primera puerta perforada (O-3), mediante fábrica de ladrillo y mortero coloreado imitando la propia roca (Fernández Rodríguez et al. 2006: 98; Fernández Rodríguez 2009: 73); vii) la eliminación del suelo y los elementos de drenaje dispuestos en 1997; viii) la excavación de una nueva zanja de drenaje a todo lo largo del tramo de corredor descubierto, pasando bajo la primera puerta perforada (O-3), y tres arquetas (Fernández Rodríguez et al. 2006: 97-98; Fernández Rodríguez 2009: 72-73): una situada entre los ortostatos O-6 y O-27, otra entre los ortostatos O-2 y O-31, y la tercera al otro lado del camino de acceso al dolmen, en dirección sureste, que comunicaba con otra zanja que evacuaría las aguas al exterior del recinto; ix) la disposición del cableado de la nueva instalación eléctrica; y (x) la disposición de un nuevo pavimento.

Por último, los trabajos desarrollados en el entorno fueron: (i) la excavación con medios mecánicos de una zanja de $0,5 \mathrm{~m}$ de anchura y $1 \mathrm{~m}$ de profundidad desde la arqueta de recogida de aguas del túmulo y del corredor de Viera, situada al otro lado del acceso al dolmen, hasta el exterior del recinto en dirección sureste (Fernández Rodríguez et al. 2006: 98; Fernández Rodríguez 2009: 73); (ii) la excavación de zanjas para instalar la iluminación eléctrica exterior; y (iii) la limpieza de la vegetación y la disposición de una nueva capa de zahorra y albero en el camino de acceso que discurre desde el lateral oeste del recinto hasta el acceso a Viera.

El dolmen de Viera no ha vuelto a conocer ninguna intervención importante con posterioridad a 2004. No obstante, sí se han hecho actuaciones en su entorno inmediato. En 2004, Manuel Romero Pérez dirigió una actividad arqueológica en el lateral sur del recinto de los dólmenes, entre Viera y la carretera Antequera-Archidona, motivada por la ejecución de la $3^{\mathrm{a}}$ fase del vallado perimetral del conjunto Menga-Viera. Durante esta intervención se abrieron tres nuevos cortes que depararon restos materiales de la Antigüedad (AA. VV. 2010: 655).

En 2007, como parte del "Proyecto Básico y de Ejecución de la Ordenación Paisajística del Campo de los Túmulos", dirigido por los arquitectos Jasone Ayerbe García y Francisco Javier Ruiz Recco (ver descripción más adelante) se ejecutó a la entrada de Viera una plazoleta con suelo de hormigón de unos $10 \mathrm{~m}$ de diámetro, conectada con el camino que conduce a los visitantes desde el edificio de Recepción inaugurado en diciembre de 2007. En octubre de 2018 la dirección del CADA realizó un agujero de aproximadamente un metro de longitud, medio metro de anchura y otro tanto de profundidad en la parte posterior del túmulo del dolmen, al parecer para la instalación de una cabina de apoyo a las actividades didácticas para visitantes. Según la información facilitada por el Servicio de Bienes Culturales de la Delegación de Málaga de la Consejería de Cultura y Patrimonio Histórico, en dicho servicio no consta ningún Proyecto de Actuación ni informe al respecto.

\section{EL ROMERAL}

Los hermanos Viera llevaron a cabo la primera excavación en el tholos de El Romeral en 1904 (Gómez-Moreno 1905: 89) poco después del descubrimiento del dolmen que llevaría su nombre. En ese 
momento el túmulo ocultaba completamente la estructura megalítica, cuyo acceso estaba obstruido. Como en Viera, la excavación en El Romeral debió consistir en una zanja realizada en la estructura tumular (Gómez-Moreno 1905: 90) para acceder al tramo de corredor descubierto y al resto de la estructura interior (Leisner y Leisner 1943: 174 y lám. 55).

En 1904-1905 se conservaban en el acceso "una alta piedra hincada y otras menores" y el interior de la estructura megalítica estaba colmatado en parte (Gómez- Moreno Martínez 1905: 91-92). En el tramo de corredor cubierto, cuatro de las diez cobijas conservadas estaban rotas (C-7, C-10, C-11, C-12), faltaba una entre las actuales cobijas segunda (C-2) y tercera (C-6), el relleno del suelo obstruía el acceso, y la mampostería de las paredes se encontraba muy deteriorada (Gómez-Moreno 1905: 92; Velázquez 1905, lám. XIX). En el relleno de la primera cámara de $0,8 \mathrm{~m}$ de altura se identificaron dos capas sedimentarias y algunos restos materiales. La mampostería de las paredes estaba también deteriorada en ciertas zonas, existiendo grandes huecos (Gómez-Moreno 1905: 92). En la segunda cámara, la mampostería también estaba en mal estado y había dos grandes socavones (Gómez-Moreno 1905: 92).

El corredor y la primera cámara estaban pavimentados con "lajas en bruto y llenos sus intersticios con piedras menores" (Gómez-Moreno 1905: 91). La segunda cámara tenía en su mitad norte una gran losa encastrada en el muro norte de la cámara circular. En cambio, el pavimento original había desaparecido por completo en su mitad sur, no sabemos si en la excavación de los hermanos Viera o antes (Gómez-Moreno 1905: 92).

Pierre Paris (1921: 22-23) mencionó otra estructura en el túmulo de El Romeral, definiéndola como "un tipo de galería curva, excavada en una masa rocosa contra la que la Cueva del Romeral parece adosada". Esta estructura no parece que fuera vista por ningún otro investigador. Cuando los Leisner (Leisner y Leisner 1943: 174) la mencionaron dejaron claro que partían de la descripción de Paris (García Sanjuán et al. 2019: 102).

En su visita, los Leisner fotografiaron los restos de un muro de mampostería perpendicular a las paredes del corredor que comunica las dos cámaras. Este muro estaba dispuesto entre el tramo propiamente dicho de corredor de mampostería y la puerta de acceso a la segunda cámara, conformada por las dos jambas (Leisner y Leisner 1943, lám. 100.1). Este muro, que no mencionaron en su descripción del monumento, sellaría e impediría el acceso a la segunda cámara en algún momento de la biografía del monumento (García Sanjuán et al. 2019: 103-104). No sabemos si el muro estaba derribado ya en 1904 o se rompió durante la ex- cavación de los hermanos Viera. Este dato es del mayor interés pues no siempre se pueden observar los dispositivos de cerramiento de los megalitos y sus cámaras.

El Romeral fue declarado Tesoro Artístico Arqueológico Nacional el 9 de agosto de 1926 y Monumento Histórico-Artístico el 3 de junio de 1931 (Ruiz González 2011: 27-29). Sin embargo, a corto plazo este reconocimiento no habría de conducir a su mejor protección y conservación. A finales de los años 1930 su estado era lamentable. La vegetación silvestre cubría el túmulo y el tramo de corredor descubierto. Las paredes de mampostería del corredor (tanto del tramo descubierto como del tramo cubierto) estaban derruidas, como ciertos sectores de las cámaras, que presentaban socavones de hasta $2 \mathrm{~m}$ de profundidad cuyos restos se acumulaban sobre los suelos. En la parte opuesta a la entrada, en el lateral norte-noreste del túmulo, había una zanja abierta de $2 \mathrm{~m}$ de longitud, 1 $\mathrm{m}$ de anchura y $1 \mathrm{~m}$ de profundidad (Giménez Reyna 1946: 32-33).

En 1940 Simeón Giménez Reyna dirigió, con la colaboración de la Delegación de Zona de Bellas Artes, una intervención en el tholos, que afectó al monumento y a su entorno. Fue sufragada por el propietario del terreno, el señor García Berdoy, presidente de la Sociedad Azucarera Antequerana y académico de la Real Academia de Bellas Artes de San Telmo de Málaga (Giménez Reyna 1946: 32). Los trabajos pretendían restaurar el túmulo y el interior del monumento y facilitar el acceso de vehículos mediante un camino delimitado por álamos (Giménez Reyna 1946: 33-34). En el propio monumento se tapó la zanja ubicada en el lateral norte-noreste, se retiraron los rellenos que ocupaban el corredor y las cámaras, se repuso la mayor parte de la mampostería que faltaba tanto en el corredor como en las cámaras, y se dispusieron las actuales cobijas C-3, C-4 y C-5 en el hueco existente entre las cobijas C-2 y C-6. Se instaló iluminación eléctrica, se arregló la cancela de hierro que cerraba el paso al interior del tholos y se colocaron a su entrada una losa que conmemoraba la restauración y un banco de piedra. A esta actuación debe corresponder también la plantación de los cipreses que han rodeado el túmulo durante décadas, visibles en las fotografías aéreas del Vuelo Americano Serie B de 1956-1957, y recientemente talados.

Solo nos constan dos actuaciones desarrolladas en El Romeral con posterioridad, de ninguna de las cuales hay demasiada documentación. La primera tuvo lugar a principios de $1996^{14}$ y consistió en la apertura

\footnotetext{
14 Expediente de remoción no autorizada en terrenos del "Dolmen El Romeral", Antequera, Unidad de Protección del Patrimonio Histórico, expediente 81/95, Archivo Histórico Provincial de Málaga, legajo 17090 .
} 
ilegal y el posterior tapado de una zanja de $300 \mathrm{~m}$ de longitud, $10 \mathrm{~cm}$ de ancho y $15 \mathrm{~cm}$ de profundidad en la parcela en la que se ubica el monumento. Aunque esta zanja atravesó toda la finca por la mitad norte, no afectó directamente al tholos. La segunda corresponde al "Proyecto Básico y de Ejecución en el Dolmen de El Romeral" redactado en 1994 y modificado en 1999 por Ciro de la Torre Fragoso. Este proyecto fue ejecutado en 2002, pero no sabemos si total o parcialmente. Solo tenemos certeza de tres actuaciones en relación con este proyecto. La primera fue el desmonte del pavimento existente en el interior del monumento por parte de un equipo de arqueólogos coordinados por la Delegación de Cultura de Málaga. Se dejó visible un testigo de la solería original de lajas de piedra en la cámara principal y es posible que se destruyera el resto del pavimento original del tholos, dado que éste había sido dejado al descubierto en 1940 y no consta que se hubiera tapado para su preservación con posterioridad. La segunda fue una nueva instalación eléctrica y la tercera el traslado al exterior de un gran bloque pétreo ubicado en el corredor (Ruiz González 2011: 49 y 151). Este bloque ha sido descrito como un menhir con un grabado oval pulido en la zona central (Bueno Ramírez et al. 2007: 297, 2008: 55, 2009: 191, 2013b: 253, 2013a: 34-35, 2017: 195). Esta 1lamativa pieza no fue mencionada por ninguno de los investigadores de mediados del siglo XX. No obstante, aparece en varias fotografías tomadas tras la restauración de 1940, por lo que puede que se hallara en las inmediaciones del monumento y se introdujera en el corredor en 1940. En 2008 fue retirado del tholos por la dirección del CADA.

\section{EL ENTORNO DE LOS MONUMENTOS}

En los últimos cuatro decenios se han llevado a cabo numerosas actuaciones en el entorno de los tres monumentos propiamente dichos. Varias de ellas tuvieron consecuencias muy significativas a efectos de investigación y conservación. A este respecto, podemos distinguir tres ámbitos espaciales diferenciados: el entorno inmediato de Menga-Viera, el Llano de Rojas y el cerro de Marimacho. Todos eran zonas de olivar en los años 1940 y 1950 según se aprecia en las fotografías aéreas. El cerro de Marimacho no experimentó ningún cambio significativo en las décadas siguientes, pero el entorno de Menga-Viera y el Llano de Rojas sí sufrieron importantes modificaciones. Como ya hemos expuesto, en 1941, 1967 y 1983-1984 se acondicionó el entorno de Menga y Viera. En el Llano de Rojas los principales cambios fueron la eliminación del olivar en la década de los 1970 y dos rebajes con maquinaria en su zona central y sur en los 1980 .
En 1985 con el cambio del contexto administrativo, la Junta de Andalucía encargó sucesivos "Proyectos de Ordenación" y "Proyectos Básicos y de Ejecución” en el denominado "Recinto Primero" o "Recinto 1" del sitio, conformado por el entorno de Menga-Viera y el Llano de Rojas. El "Recinto 2" correspondiente al tholos de El Romeral quedó generalmente al margen. Los arquitectos Enrique Haro Ruiz y Manuel Salado Ordoñez desarrollaron el "Proyecto de Ordenación General del Recinto Primero del Conjunto Arqueológico Dólmenes de Antequera", aprobado por la Junta en 1990 (Ruiz González 2011: 38-41 y 150). Estas actuaciones ya han sido descritas en las páginas precedentes.

Las otras actuaciones fueron adjudicadas a la empresa Ferrovial S.A., acometiéndose entre 1991 y 1993 la ordenación del recinto y los primeros trabajos en el edificio de recepción, investigación y aparcamientos del Llano de Rojas. Este proyecto no fue ejecutado en su totalidad, quedando paralizado para su modificación en 1993. No obstante, constituyó la base de otros futuros (Ruiz González 2011: 38-41 y 150). Salado Ordoñez modificó el primer proyecto en 1993. Destaca el cambio en el programa de usos del edificio parcialmente construido en el Llano de Rojas, que pasó a concebirse como Museo Arqueológico. Este nuevo proyecto fue aprobado en 1994 y ejecutado en parte entre 1997 y 1998, aunque finalmente fue paralizado en 1998 (Ruiz González 2011: $42-48$ y 151). A pesar de la redacción de múltiples proyectos en 2003, 2005 y 2007 (Ruiz González 2011: 53), en diciembre de 2007 se inauguraron tan solo el Centro de Recepción, dos plataformas para aparcamientos, el Observatorio del Caminante y el Centro Solar Michael Hoskin (Ruiz González 2011: 157-158). En cambio, el edificio concebido como Museo permaneció sin terminar y en estado de abandono hasta que en 2018 se retomó su reforma como parte de las exigencias planteadas por UNESCO para la declaración del sitio como Patrimonio Mundial.

En 2005, y en el marco de la actuación arqueológica dirigida por Verónica Navarrete Pendón en Menga, antes descrita, se desarrollaron varios trabajos en el entorno de Menga y Viera. Por un lado, se retiró con retroexcavadora el arbolado plantado en las actuaciones de 1941 y 1983-1984, abriéndose para ello un número indeterminado de hoyos. Por otro, se efectuaron rebajes de tierras con el objetivo de construir el camino que discurre desde el denominado 'Centro Solar Michael Hoskin' en dirección a Viera. Estas actuaciones contaron con un seguimiento arqueológico, pero no existe documentación detallada del mismo (Mora Molina et al. 2018: 28 y 45).

Desde 2006, la Dirección General de Bienes Culturales, encargó la redacción de otros proyectos para 
la Ordenación del Conjunto y para la terminación del Centro de Interpretación y del Edificio Sede del Conjunto a otros arquitectos. Destacan el "Proyecto Básico y de Ejecución de la Ordenación Paisajística del Campo de los Túmulos", redactado en 2006 por Jasone Ayerbe García y Francisco Javier Ruiz Recco, y el "Proyecto Básico de Ordenación del Recinto Primero del Conjunto Arqueológico Dólmenes de Antequera", presentado en 2009 por José Ramón Menéndez de Luarca Navia Osorio y Miguel Rodríguez.

El primero de ellos fue ejecutado parcialmente en 2007, modificado en 2008 y reiniciado de nuevo en 2008 , finalizando en 2009, siendo la empresa adjudicataria de los trabajos Rofez Construcciones S.L. (Ruiz González 2011: 61-69 y 159). El proyecto tenía dos objetivos: la construcción del camino que conduce actualmente a los dólmenes de Menga y Viera desde el "Centro Solar Michael Hoskin" y la plantación de arbolado y matorral en el entorno de ambos monumentos (Ayerbe García y Ruiz Recco 2009). Estos trabajos llevaron aparejadas una "Actividad Arqueológica Preventiva" del tipo "Control arqueológico de movimientos de tierras". Esta actuación terminó con un rebaje de $0,4-0,8 \mathrm{~m}$ con máquina retro-excavadora para el trazado de tres tramos de un nuevo camino. El Tramo 1 de $185 \mathrm{~m}$ de longitud y $3 \mathrm{~m}$ de anchura discurre desde el 'Centro Solar Michael Hoskin' en dirección al vallado del conjunto arqueológico. El Tramo 2 continúa junto a la valla hasta situarse en paralelo al lateral sureste del dolmen de Viera. El Tramo 3 gira en dirección a Menga y discurre en paralelo al lateral sur de Viera hasta conectar con el camino que conduce a Menga por su lateral oeste-noroeste ${ }^{15}$. Para el segundo objetivo se abrieron 73 nuevos hoyos para la plantación de arbolado $^{16}$.

El segundo proyecto fue ejecutado en 2011, contemplando trabajos de eliminación de vertidos terrígenos, plantación de árboles, y apertura de nuevos caminos en el denominado Recinto Primero de los Dólmenes de Antequera. Afectó principalmente al Llano de Rojas (Ruiz González 2011: 161). Debido a la cercanía de los dólmenes de Menga y Viera y de los yacimientos Marimacho y Carnicería de los Moros, hubo un seguimiento denominado "Actividad Arqueológica Preventiva de Control de Movimientos de Tierras en el Proyecto de Ordenación del Conjunto Arqueológico de los Dólmenes de Antequera (Málaga)", dirigida por el arqueólogo David García González. El objetivo era salvaguardar cualquier resto arqueológico

\footnotetext{
15 Véase nota 16.

16 D. García González, "Memoria final de la actividad arqueológica preventiva de control de movimiento de tierras del proyecto de ajardinamiento en el conjunto dolménico de Antequera (Málaga)". Memoria inédita. Delegación Provincial de Cultura de Málaga, 2007.
}

y garantizar que se tomaban las medidas necesarias para su documentación y protección ${ }^{17}$.

El sitio de Marimacho tiene evidencias de ocupación en la Edad del Cobre. Está situado entre el Llano de Rojas al oeste y el arroyo de La Villa al este y, hasta donde sabemos, ha experimentado las siguientes intervenciones: (i) los hoyos realizados en 1996 por el expolio de tres tumbas ${ }^{18}$; ii) la apertura de nueve cortes en la zona baja de la ladera oriental, como parte de una actuación de control de la ronda de circunvalación de la ciudad (Marqués Merelo et al. 2004a: 242); y iii) los movimientos de tierra desarrollados en 2014 para la construcción de un tramo de acera paralelo a la carretera N-354 Antequera-Archidona, que bordea el CADA por su lateral sur (García González et al. 2014: 247-249).

\section{DISCUSIÓN}

Como se desprende de la exposición previa, la historia de las intervenciones que han tenido repercusiones para la integridad física de los dólmenes de Antequera y su entorno inmediato es larga, densa y compleja. Incluye, según nuestra revisión, al menos 26 actuaciones: (i) 7 actividades arqueológicas entre las décadas de 1840 y 1930, entre ellas 5 excavaciones irregulares y sin metodología arqueológica y 2 obras de restauración; (ii) 3 actividades de restauración y/o acondicionamiento entre 1940 y 1984; (iii) 16 intervenciones entre 1985 y 2019, correspondiendo 5 a excavaciones arqueológicas, 6 a obras de conservación y/o acondicionamiento y otras 5 llevaron aparejadas excavaciones de apoyo.

Las intervenciones más tempranas causaron daños irreparables a los megalitos, como, por ejemplo, la rotura de la losa de cabecera de Menga por parte de Rafael Mitjana y Ardison, o el desmonte de la mitad septentrional de su túmulo por la apertura del camino para tránsito de vehículos rodados hasta la entrada en la intervención de Prieto Moreno de 1941. Cuando se efectuaron esas actuaciones no existían cuerpos disciplinares basados en la experiencia, normativa en los que pudieran basarse, ni un marco institucional consolidado que les diera respaldo. Paradójicamente, a partir de 1985, año de la transferencia de competencias en materia de Patrimonio Histórico a la Junta de Andalucía, cuando unos y otra existían a nivel nacional e internacional, también

\footnotetext{
17 D. García González, "Informe preliminar. Actividad Arqueológica Preventiva de Control de Movimiento de Tierras en el Proyecto de Ordenación del Conjunto Arqueológico de los Dólmenes de Antequera". Memoria inédita. Delegación Provincial de Cultura de Málaga, 2011.

18 Expediente 89/96, Consejería de Cultura, Delegación Provincial de Málaga.
} 
hubo intervenciones que afectaron a la integridad física de los monumentos, y en gran número. En este sentido, es posible distinguir varios problemas fundamentales:

1) Inadecuación de criterios: restauración y ordenación. La gran mayoría de los llamados "Proyectos de Ordenación" y los "Proyectos Básicos y de Ejecución" realizados en el emplazamiento de Menga y Viera y en el Llano de Rojas desde 1990 hasta la actualidad fueron diseñados exclusivamente por arquitectos, y a partir de criterios funcionales y estéticos estrictamente contemporáneos. No se tuvieron en cuenta la edad, el carácter o la morfología de los propios monumentos, ni el valor de sus relaciones paisajísticas con el entorno (de carácter esencial en el caso de Menga, como ha quedado demostrado en las investigaciones recientes), ni el del entorno natural donde se emplazaban. En casi todos los casos, los arquitectos responsables de estas intervenciones carecían de experiencia previa de intervención en monumentos megalíticos (o sitios arqueológicos) y no contaron con el asesoramiento necesario por parte de equipos científicos poseedores de dicha experiencia. Así se explica, por ejemplo, la brutal transformación del aspecto exterior del dolmen de Viera en la intervención de 2004. La gran ampliación del tamaño de su túmulo, en extensión y en altura, además de la transformación del aspecto de su corredor lo convierten en un 'falso histórico' que ignora el principio de autenticidad exigible a las intervenciones en bienes culturales. Otro caso es la actuación de 'limpieza' de paramentos interiores llevada a cabo en Menga en 2001 y 2003 por un equipo solo de restauradores, sin geólogos que conocieran las propiedades físicas de las rocas en la que estaban manufacturados los soportes pétreos, ni arqueólogos especialistas en los tratamientos pétreos de los soportes megalíticos.

2) Inadecuación de criterios: excavaciones arqueológicas. Una tónica de las intervenciones en los monumentos antequeranos es el reiterado abuso de la excavación arqueológica como método. La experiencia más reveladora se da a partir de 1985 con las actuaciones de la UMA: 33 cortes en Menga, 25 en Viera y otros 10 en el entorno de los monumentos en sucesivas campañas. Estos cortes generaron problemas ulteriores para la propia integridad y sostenibilidad de los monumentos, como ya se ha detallado. Además, nunca se publicaron los resultados de esta intervención, y a fecha de hoy no se han entregado los materiales recogidos y el registro documental obtenido durante la misma en el Museo de Málaga, la institución responsable de su custodia. La posibilidad de su estudio por parte de otros equipos lleva así bloqueada más de veinte años. Otro ejemplo es la intervención llevada a cabo en el interior del dolmen de Menga en la primavera de 2005 . Inicialmente prevista como de apoyo para la instalación de un nuevo sistema eléctrico, implicó la apertura de varios cortes en el exterior del monumento, sin que las necesidades de la obra eléctrica lo justificase.

3) Encarnizamiento urbanístico: como resultado de la trayectoria de actuaciones expuesta, el entorno de los monumentos es hoy un área intensamente urbanizada con diversos caminos y plazoletas con pavimentos hormigonados, aparcamientos, un Centro de Recepción de Visitantes y un llamativo edificio, originalmente concebido como Centro de Interpretación de la Prehistoria de Andalucía, ahora en proceso de transformación en Museo de Sitio. El ensañamiento urbanístico en el entorno de los monumentos, conectado con el problema de inadecuación de criterios ya mencionado, ha generado una gradual cosificación de los megalitos, y la alienación de su original carácter de monumentos íntimamente relacionados con la naturaleza circundante (formaciones naturales, topografía, agua, perspectivas visuales, efectos de iluminación solar, etc.). Los ejemplos de intervenciones en sitios megalíticos de análoga importancia como Stonehenge, Newgrange o los monumentos de las Islas Orcadas muestran el camino a seguir en la ordenación de los monumentos neolíticos y su entorno. La vía es el alejamiento de las instalaciones modernas a varios kilómetros de los monumentos, su ocultación topográfica y visual, y el cumplimiento de un principio de mínima invasión de los bienes y mínimo impacto paisajístico. Esto es exactamente lo contrario de lo que se ha hecho en Antequera (Carrera Ramírez 2011).

4) Falta de proporcionalidad: el común denominador de muchas de las intervenciones en el sitio de los dólmenes de Antequera es su falta de proporción entre los objetivos perseguidos y los medios utilizados. El resultado es que la intervención arqueológica se convierte en sí misma en una fuente de problemas graves de conservación cuya solución exige sucesivas actuaciones, todas agresivas. El intento de solucionar esos problemas no puede degenerar en la creación de falsos históricos que deforman monumentos megalíticos con 6000 años de antigüedad a criterio de una única persona carente de experiencia previa en la materia y/o criterios técnicos y científicos sólidos. Tampoco la inclusión de los dólmenes de Antequera en la lista de Patrimonio Mundial de UNESCO puede convertirse en pretexto para una estrategia de sobreexplotación turística. En los últimos dos años (básicamente, después de la declaración de la UNESCO), el CADA ha comenzado a ofrecer representaciones teatrales y musicales que concentran audiencias en el interior del dolmen de Menga durante prolongados periodos de tiempo. Esta estrategia no guarda proporción con respecto al objetivo general de difusión de los bienes culturales en cuestión, y generará en el futuro sus pro- 
pios problemas de conservación, como se ha comprobado, por no salir de la propia provincia de Málaga, en la cueva de Nerja. Esta preocupante tendencia a la cosificación, masificación y banalización en la estrategia de difusión del sitio resulta tanto menos adecuada cuanto que, a fecha de hoy, y a la espera de que se inaugure el futuro Museo del Sitio, el visitante carece de herramientas cualificadas (p. ej., una cartelería in situ), que le sirvan para entender lo que está viendo.

\section{CONCLUSIÓN}

Resulta de la mayor importancia reflexionar sobre las luces y las sombras de los últimos 180 años de intervenciones de los dólmenes de Antequera y extraer las necesarias conclusiones. Sin duda, dicha trayectoria aúna el esfuerzo sincero, y muchas veces desinteresado, de decenas de personas que creyeron en la excepcional importancia patrimonial y científica del sitio y que, colectivamente, han logrado que el mismo adquiera el rango que merece a nivel nacional e internacional. Podría parecer que la declaración por parte de UNESCO en 2016, por ser un innegable éxito en sí misma, condona y refrenda todo lo realizado hasta ese momento, o después. Nada más lejos de la realidad. Precisamente, la declaración de UNESCO obliga a aplicar los criterios más exigentes y cualificados en todo lo concerniente a la conservación, investigación y difusión del sitio, que además va a ser objeto de un mayor escrutinio por parte de la comunidad científica nacional e internacional, por no decir de la propia UNESCO.

En ese sentido, creemos que todas las actuaciones desarrolladas en los megalitos antequeranos y su entorno deben adherirse a un conjunto de criterios cuidadosamente establecidos por expertos, con base técnica y científica. Es muy importante que la tarea de supervisar y revisar todas las intervenciones que se propongan en el sitio, evitando los problemas de inadecuación de criterios, falta de proporcionalidad y encarnizamiento urbanístico que se han dado en el pasado, recaiga sobre un órgano multidisciplinar de especialistas en patrimonio megalítico que cumpla su función de manera independiente. El papel de este órgano es tanto más crucial cuanto que dicha tarea de supervisión técnica debe ser colegiada y fundamentada en el mérito, la capacidad y la experiencia, no pudiendo recaer en la dirección del órgano administrativo al que en cada caso y en cada momento le corresponda la gestión del sitio. Como ejemplos de los criterios que deben regir dichas intervenciones, proponemos los siguientes:

1) Ser dirigidas por personal con contrastada experiencia en la investigación, excavación y conserva- ción de arquitecturas megalíticas y depósitos prehistóricos asociados.

2) Contar con el asesoramiento del equipo o los equipos que en cada momento sean responsables de su investigación, de manera que las intervenciones estén informadas por los datos y la experiencia científicos disponibles respecto al sitio y sus monumentos, y el conocimiento derivado pueda ser contrastado con el previamente existente.

3) Una planificación cuidadosa y racional con objetivos explícitos, proporcionados y justificados, de manera que la metodología aplicada durante cada intervención se ajuste a la consecución de los mismos.

4) Minimizar los trabajos invasivos o destructivos, evitando en todo caso ocasionar daños a las arquitecturas megalíticas, a sus depósitos estratigráficos y materiales asociados y a su entorno. Ello incluye minimizar el uso de la excavación arqueológica como método, muy especialmente en los dólmenes de Menga y Viera, donde se ha practicado en exceso.

5) Las intervenciones arqueológicas deben incluir financiación suficiente tanto para el trabajo de campo en condiciones de máximas garantías técnicas como también para completar el trabajo post-excavación, incluyendo los estudios de materiales y pruebas científicas necesarias, así como su ulterior publicación.

6) Las restauraciones, obras de conservación y de tapado de cortes arqueológicos deben emplear materiales respetuosos con la naturaleza de estos bienes evitando los que sean anacrónicos y/o puedan generar ulteriores daños a los monumentos a corto o a largo plazo.

7) Contemplar la publicación de las actuaciones realizadas y los resultados obtenidos de la forma más exhaustiva en el plazo más breve posible tras su finalización. Otra cosa dificulta la correcta tutela, protección y difusión, e imposibilita la ulterior investigación de los monumentos.

8) Contar con un equipo técnico y científico experimentado y multi-disciplinar que incluya especialistas de diversas disciplinas (arqueólogos, geólogos, restauradores y arquitectos), con trayectorias solventes y contrastadas en sitios con monumentos megalíticos. Este equipo debe integrarse en un órgano colegiado responsable de la supervisión de las intervenciones en el sitio, y que produzca las necesarias directrices técnicas para todo tipo de actuaciones, desde trabajos de campo (criterios de registro, nomenclatura y publicación), hasta restauración y puesta en valor, dentro de un plan de acción que evalúe todos los problemas de conservación presentados por el sitio y proponga las soluciones más apropiadas.

9) Retomar la línea de publicaciones técnicas que, encabezada por la revista Menga, el CADA tuvo entre 2010 y 2017 y que, inexplicablemente, ha dejado de 
existir. Las publicaciones científicas y técnicas aparecidas en ese periodo (ocho números de la revista Men$g a$, y dos monográficos de la misma) fueron de enorme importancia en el proceso de selección de la candidatura del sitio por parte de UNESCO, y dieron un marco de solvencia a las actuaciones realizadas en ese periodo, a la vez que sirvieron para traer a la luz los resultados de intervenciones inéditas, estudios puntuales, reuniones científicas, etc.

Sería muy recomendable que estos criterios fueran tenidos en cuenta dentro de los proyectos de actuación arqueológica, conservación y musealización contemplados en el "Plan Director del Conjunto Arqueológico Dólmenes de Antequera (2018/2025)" aprobado por Orden de la Consejería de Cultura de 4 de mayo de 2018 (AA. VV. 2018). Pero con independencia de este punto, creemos que es de la mayor importancia que la tarea de gestión de este sitio se base en criterios técnicos, y ciertamente no políticos, emanados de una comisión técnica independiente y solvente, compuesta por especialistas de experiencia contrastada.

\section{ANEXOS}

En la edición electrónica de este artículo, disponible en libre acceso en la página web de la revista, se incluyen las siguientes figuras:

Anexo 1: Planimetría de las intervenciones llevadas a cabo en el dolmen de Menga (Antequera, Málaga) en los últimos 40 años.

Anexo 2: Planimetría de las intervenciones llevadas a cabo en el dolmen de Viera (Antequera, Málaga) en los últimos 40 años.

\section{BIBLIOGRAFÍA}

AA. VV. 1993: "Intervenciones Arqueológicas. Málaga". Anuario Arqueológico de Andalucía / 1991, I. Sumario. Junta de Andalucía. Cádiz.

AA. VV. 2010: "Memoria de gestión de las actividades arqueológicas de la provincia de Málaga". Anuario Arqueológico de Andalucía 2004.2. Málaga. Junta de Andalucía. Sevilla.

AA. VV. 2018: Plan Director del Conjunto Arqueológico Dólmenes de Antequera 2018/2025. Junta de Andalucía. Sevilla.

Amador de los Ríos, R. [c.a. 1907]: Catálogo de los monumentos históricos y artísticos de la provincia de Málaga. [Manuscrito]: formado en virtud de R.O. de 22 de enero de 1907 http://www.bibliotecavirtualdeandalucia.es/catalogo/es/consulta/registro.cmd?id=1014329

Aranda Jiménez, G.; García Sanjuán, L; Mora Molina, C.; Moreno Escobar, M. C.; Riquelme Cantal, J. A.; Robles Carrasco, S. y Vázquez Paz, J. 2015: "Evidencias de asentamiento y prácticas funerarias en los dólmenes de Menga y Viera en la Antigüedad. La intervención de 1988". Menga. Revista de Prehistoria de Andalucia 06: 253-289.

Ayerbe García, J. y Ruiz Recco, F. J. 2009: "Ordenación espacial del campo de los túmulos". En B. Ruiz González (ed.): Dólmenes de Antequera. Tutela y valorización hoy, PH Cuadernos 23, Junta de Andalucía. Sevilla: 278-284.
Barrera, J. 1896: "España Vieja. La Cueva de Menga”. Blanco y Negro Revista Ilustrada 286: 1.

Bueno Ramírez, P.; Balbín Behrmann, R. de y Barroso Bermejo R. 2007 "Ideología de los primeros agricultores en el sur de Europa: las más antiguas cronologías del arte megalítico ibérico". Cuaderno de Arte Rupestre 4: 281-312.

Bueno Ramírez, P.; Balbín Behrmann, R. de y Barroso Bermejo, R. 2008: "Dioses y antepasados que salen de las piedras". En L. García Sanjuán (ed.): Patrimonio megalítico: más allá de los límites de la Prehistoria. PH Boletín del Instituto Andaluz del Patrimonio Histórico, Monográfico 67, Junta de Andalucía. Sevilla: 46-61.

Bueno Ramírez, P.; Balbín Behrmann, R. de y Barroso Bermejo, R. 2009: "Análisis de las grafías megalíticas de los dólmenes de Antequera y su entorno". En B. Ruiz González (ed.): Dólmenes de Antequera. Tutela y valorización hoy, PH Cuadernos 23, Junta de Andalucía. Sevilla: 186-197.

Bueno Ramírez, P.; Balbín Behrmann, R. de y Barroso Bermejo R. 2013a: "Símbolos para los muertos, símbolos para los vivos. Arte megalítico en Andalucía”. En J. Martínez García y M. S. Hernández Pérez (eds.): Actas del II Congreso de Arte Rupestre Esquemático en la Península Ibérica. Comarca de Los Vélez (Vélez Blanco, Almería 2010): 25-47. Almería.

Bueno Ramírez, P.; Balbín Behrmann, R. de y Barroso Bermejo, R. 2017: "Steles, time and ancestors in the megaliths of Antequera, Málaga (Spain)". Menga. Revista de Prehistoria de Andalucía 08: 193-219.

Bueno Ramírez, P.; Balbín Behrmann, R. de; Barroso Bermejo, R.; Carrera Ramírez, F. y Ayora Ibáñez, C. 2013b: "Secuencias de arquitecturas y símbolos en el dolmen de Viera (Antequera, Málaga, España)". Menga. Revista de Prehistoria de Andalucía 04: 251-266.

Carrera Ramírez, F. 2009: "Sobre las intervenciones en los sepulcros de Antequera: criterios del pasado, opiniones para el futuro". En B. Ruiz González (ed.): Dólmenes de Antequera. Tutela y valorización hoy. Junta de Andalucía. Sevilla: 230-241.

Carrera Ramírez, F. 2011: "Crónica del fracaso. Tipos y criterios de intervención en monumentos megalíticos". Memorial Luis Siret. I Congreso de Prehistoria de Andalucía. La tutela del patrimonio prehistórico: 423-435. Sevilla.

Díaz-Guardamino Uribe, M.; García Sanjuán, L.; Wheatley, D.; Lozano Rodríguez, J. A.; Rogerio-Candelera, M. A. y Casado Ariza, L. 2020: "Late prehistoric stelae and persistent places: a multi-disciplinary review of the evidence at Almargen (Lands of Antequera, Spain)". Cambridge Archaeological Journal 30 (1): 69-96.

Fernández Rodríguez, L. E. 2009: "La interacción entre los proyectos de restauración de estructuras y la investigación arqueológica. Caso del sepulcro megalítico de la Cueva de Viera". Caetaria 6-7: 61-74.

Fernández Rodríguez, L. E.; Romero Pérez, M. y Ruiz de la Linde, R. 2006: "Resultados preliminares del control arqueológico de los trabajos de consolidación del sepulcro megalítico de Viera, Antequera". Anuario Arqueológico de Andalucía 2003: 89-99.

Ferrer Palma, J. E. 1997a: "Proyecto de reconstrucción arquitectónica y paleoambiental en la necrópolis megalítica de Antequera (19851991): aspectos metodológicos”. En J. M. Martín Ruiz, J. A. Martín Ruiz y P. J. Sánchez Bandera (eds.): Arqueología a la carta. Relaciones entre teoría y método en la práctica arqueológica. Diputación Provincial de Málaga. Málaga: 119-144.

Ferrer Palma, J. E. 1997b: "La necrópolis megalítica de Antequera. Proceso de recuperación arqueológica de un paisaje holocénico en los alrededores de Antequera, Málaga". Baetica. Estudios de Arte, Geografia e Historia 19: 351-370.

Ferrer Palma, J. E.; Marqués Merelo, I.; Baldomero Navarro, A. y Aguado Mancha, T. 2004: "Estructuras tumulares y procesos de construcción en los sepulcros megalíticos de la provincia de Málaga: la necrópolis megalítica de Antequera". Los enterramientos en la Península Ibérica durante la Prehistoria Reciente. Mainake 26: 117-210.

García González, D.; Morgado Rodríguez, A.; Martínez-Sevilla, F.; Martínez Sánchez, R. M.; Fernández Martín, S.; Gutiérrez-Rodríguez, M. y Sánchez Bandera, P. 2014: "Intervención en el cerro de Marimacho (Antequera, Málaga): primeras evidencias de la existencia de un foso". Menga. Revista de Prehistoria de Arqueología 05: $247-257$ 
García Sanjuán, L. 2009: “Criterios para un programa de investigación. Sociedades, territorios y paisajes en la Prehistoria de Antequera". En B. Ruiz González (ed.): Dólmenes de Antequera. Tutela y valorización hoy. Junta de Andalucía. Sevilla: 112-127.

García Sanjuán, L. y Lozano Rodríguez, J. A. 2016: "Menga (Andalusia, Spain): Biography of an exceptional megalithic monument". En L. Laporte y C. Scarre (eds.): The Megalithic Architectures of Europe. Oxbow. Oxford: 3-16.

García Sanjuán, L.; Montero Artús, R. y Mora Molina, C. 2021: "Waterscapes through time: The Menga well as a unique hydraulic resource in its geographic and historical context”. En M. Bartelheim, L. García Sanjuán y R. Hardenberg (eds.): Human-Made Environments: The development of landscapes as resource assemblages. Ressourcen Kulturen 15, Tübingen University Press. Tübingen.

García Sanjuán, L. y Mora Molina, C. (eds.) 2018: La intervención de 2005 en el Dolmen de Menga. Temporalidad, biografia y cultura material en un Monumento del Patrimonio Mundial. Monografías Arqueología, Junta de Andalucía y Universidad de Sevilla. Sevilla.

García Sanjuán, L.; Mora Molina, C. y Bartelheim, M. 2019: "The Antequera megalithic site in the work of Georg and Vera Leisner: A review". SPAL 28 (2): 93111.

García Sanjuán, L; Mora Molina, C. y Montero Artús, R. 2018: "El pozo de Menga. Una estructura hidráulica excepcional". En L. García Sanjuán y C. Mora Molina (eds.): La intervención de 2005 en el Dolmen de Menga. Temporalidad, biografia y cultura material en un Monumento del Patrimonio Mundial. Monografías Arqueología, Junta de Andalucía y Universidad de Sevilla. Sevilla: 325-353.

García Sanjuán, L. y Wheatley, D. W. 2009: "El marco territorial de los dólmenes de Antequera: valoración preliminar de las primeras investigaciones". En B. Ruiz González (ed.): Dólmenes de Antequera. Tutela y valorización hoy. Junta de Andalucía. Sevilla: 128-143.

García Sanjuán, L.; Wheatley, D. W.; Díaz-Guardamino Uribe, M.; Mora Molina, C.; Sánchez Liranzo, O. y Strutt, K. 2015: "Evidence of Neolithic activity at La Peña de los Enamorados (Antequera, Málaga): intensive surface survey, geophysics and geoarchaeology at the site of Piedras Blancas I". Menga. Revista de Prehistoria de Andalucía 06: 211-252.

Giménez Reyna, S. 1946: Memoria Arqueológica de la Provincia de Málaga hasta 1946. Informes y Memorias 12, Comisaría General de Excavaciones Arqueológicas, Ministerio de Educación Nacional. Madrid.

Giménez Reyna, S. 1968: Los Dólmenes de Antequera. Publicaciones de la Biblioteca Antequerana de la Caja de Ahorros y Préstamos de Antequera. Antequera.

Gómez-Moreno Martínez, M. 1905: “Arquitectura tartesia: la necrópoli de Antequera". Boletín de la Real Academia de la Historia XLVII. 81-132.

Hancock, A. M. 1882: "Prehistoric discoveries in the South of Spain". Transactions of the Anthropological Society of Washington 1: 66-68.

Harlé, E. 1887: "Le dolmen de Antequera". Matériaux pour l'histoire primitive et naturelle de l'homme. Revue Mensuelle Illustrée, XXI année, 3. ${ }^{a}$ série, tome IV: 80-82.

Haro Ruiz, E. 1990: "Ordenación del Conjunto Dolménico de Antequera". Monumentos y proyecto. Jornadas sobre criterios de intervención en el Patrimonio Arquitectónico. Ministerio de Cultura. Madrid: 94-99.

Hemp, W. J. 1934: "The passages graves of Antequera, and Maes Howe, Orkey". The Antiquaries Journal 14 (4): 404-413.

Leisner, G. y Leisner, V. 1943: Die Megalithgräber der Iberischen Halbinsel. Erster Teil: Der Süden. Verlag Von Walter de Gruyter und Co. Berlín.
Lozano Rodríguez, J. A.; Pérez Varela, L. A.; Rodríguez Ariza, O.; Mora Molina, C. y García Sanjuán, L. 2018: "Análisis sedimentológico de rellenos excavados en 2005 en el dolmen de Menga". En L. García Sanjuán y C. Mora Molina (eds.): La Intervención de 2005 en el Dolmen de Menga. Temporalidad, biografia y cultura material en un Monumento del Patrimonio Mundial. Monografías Arqueología, Junta de Andalucía y Universidad de Sevilla. Sevilla: 87-99.

Marqués Merelo, I.; Aguado Mancha, T.; Baldomero Navarro, A. y Ferrer Palma, J. E. 2004a: "Proyectos sobre la Edad del Cobre en Antequera (Málaga)". II-III Simposios de Prehistoria Cueva de Nerja. III Simposio. Las primeras sociedades metalúrgicas de Andalucía. Homenaje al profesor Antonio Arribas Palau. Fundación Cueva de Nerja. Málaga: 238-260.

Marqués Merelo, I.; Ferrer Palma, J. E.; Aguado Mancha, T. y Baldomero Navarro, A. 2004b: "La necrópolis megalítica de Antequera (Málaga): Historiografía y actuaciones recientes". Baetica. Estudios de Arte, Geografia e Historia 26: 173-189.

Mergelina, C. de 1922: "La necropoli tartesia de Antequera". Sociedad Española de Antropología, Etnografía y Prehistoria. Actas y Memorias, año I, tomo I, cuaderno I, memoria IV, 3. a sección: 37-90.

Mitjana y Ardison, R. 1847: Memoria sobre el Templo Druida hallado en las cercanías de la Ciudad de Antequera. Imprenta de D. José Martínez Aguilar. Málaga.

Mora Molina, C.; García Sanjuán, L.; Navarrete Pendón, V. y Fernández Rodríguez, L. E. 2018: "La intervención de 2005 en el dolmen de Menga: planteamiento, estructuras y estratigrafía”. En L. García Sanjuán y C. Mora Molina (eds.): La Intervención de 2005 en el Dolmen de Menga. Temporalidad, biografía y cultura material en un Monumento del Patrimonio Mundial. Monografías Arqueología. Junta de Andalucía y Universidad de Sevilla. Sevilla: 27-85.

Mortillet, A. de 1921: "Le Dolmen d'Antequera". L'Avancement des Sciences fusionnée avec L'Association Scientifique de France. Compte Rendu de la 44 Session. Strasbourg: 475-480.

Obermaier, H. 1919: El dolmen de Matarrubilla (Sevilla). Junta para la Ampliación de Estudios e Investigaciones Científicas, Comisión de Investigaciones Paleontológicas y Prehistóricas, Memoria 26, Museo Nacional de Ciencias Naturales. Madrid.

Paris, P. 1921: Promenades Archéologiques en Espagne. Éditions Ernest Leroux. París.

Rallo Gruss, A. 2005: Discursos históricos de Antequera I. Diputación Provincial de Málaga. Málaga.

Rojas y Rojas, T. de 1861: "La Cueva de Menga". El Museo Universal 37: 295-296.

Rojas y Rojas, T. de 1874: "La Cueva de Menga". El Genil. Semanario de Literatura: 15-18, 57-58, 61-62, 65-66 y 73-74

Rojas y Rojas, T. de 1879: Historia de Antequera I. Imprenta de M. Pérez de la Manga. Antequera.

Ruiz González, B. (ed.) 2011: El Conjunto Arqueológico Dólmenes de Antequera. Documento de Avance del Plan Director, III. Institucionalización. Junta de Andalucía. Sevilla.

Sánchez-Cuenca López, J. I. 2011: Menga en el siglo XIX. El más bello y perfecto de los dólmenes conocidos. Menga. Revista de Prehistoria de Andalucía. Monografías 2, Junta de Andalucía. Sevilla.

Tenison, L. 1853: Castile and Andalucia. Richard Bentley. London.

Velázquez Bosco, R. 1905: "Cámaras sepulcrales descubiertas en término de Antequera". Revista de Archivos, Bibliotecas y Museos 5: $1-7$. 